Illinois State University

ISU ReD: Research and eData

Theses and Dissertations

$10-31-2013$

\title{
Self-Expansion Motivation and Romantic Liking in Relationship Initiation
}

Nicole Melissa Hilaire

Illinois State University, nicolemhilaire@gmail.com

Follow this and additional works at: https://ir.library.illinoisstate.edu/etd

Part of the Social Psychology Commons

\section{Recommended Citation}

Hilaire, Nicole Melissa, "Self-Expansion Motivation and Romantic Liking in Relationship Initiation" (2013). Theses and Dissertations. 59.

https://ir.library.illinoisstate.edu/etd/59

This Thesis is brought to you for free and open access by ISU ReD: Research and eData. It has been accepted for inclusion in Theses and Dissertations by an authorized administrator of ISU ReD: Research and eData. For more information, please contact ISUReD@ilstu.edu. 


\title{
SELF-EXPANSION MOTIVATION AND ROMANTIC LIKING IN RELATIONSHIP INITIATION
}

\author{
Nicole M. Hilaire
}

77 Pages

December 2013

Self-expansion, the motivation for people to learn, explore, and grow, is facilitated by novel and challenging activities; often with close others (Aron \& Aron, 1996). The current studies were designed to replicate and extend Mattingly, McIntyre, and Lewandowski's (2012) experiment on self-expansion opportunity. Highly approachoriented individuals reported greater liking for potential partners who offered many opportunities to self-expand, whereas less approach-oriented individuals rated potential partners similarly across the differing levels of self-expansion opportunity.

In Study 1, I sought to alleviate the negative wording used to describe low selfexpansion opportunity in used by Mattingly and colleagues (2012), which described future experiences with a potential partner as "dull and boring." The current study compared this description of low self-expansion opportunity with an affect-neutral alternative, "familiar and comfortable." Two hundred and twenty-six students from a Midwestern university completed measures of approach and avoidance motivation before reading and reacting to a hypothetical scenario about meeting an attractive, opposite-sex stranger. My analyses revealed that the original vignette constructed for Mattingly et al.'s (2012) study produced significantly lower liking than the affect-neutral vignette that I 
created for the current study. That is, their vignette may have biased participants' reactions to the hypothetical target, using language to describe a low self-expanding target as "dull and boring."

Study 2 was designed to investigate the associations among social motives, selfexpansion opportunity, and romantic liking using a live-interaction paradigm. In this study, 60 pairs of heterosexual, romantically unattached opposite-sex strangers spent 20 minutes getting acquainted with one another in a structured interaction. Contrary to my hypothesis, individuals' social motives (approach motivation, avoidance motivation, curiosity, and desire for social intimacy) did not affect their ratings of self-expansion opportunity or liking in the live-interaction context. However, perceptions of similarity, compatibility, and self-expansion opportunity were strongly and positively associated with liking. The current studies contributed to the current literature by increasing the precision of the self-expansion model and examining self-expansion motivation in a live interaction context. 
SELF-EXPANSION MOTIVATION AND ROMANTIC LIKING

IN RELATIONSHIP INITIATION

NICOLE M. HILAIRE

A Thesis Submitted in Partial Fulfillment of the Requirements for the Degree of

MASTER OF SCIENCE

Department of Psychology

ILLINOIS STATE UNIVERSITY

2013 
SELF-EXPANSION MOTIVATION AND ROMANTIC LIKING

IN RELATIONSHIP INITIATION

NICOLE M. HILAIRE

COMMITTEE MEMBERS:

Susan Sprecher, Chair

Corinne Zimmerman, Chair 


\section{ACKNOWLEDGMENTS}

I would like to thank my committee, Drs. Sue Sprecher and Corinne Zimmerman, for their endless guidance and support throughout my years at Illinois State.

This thesis is dedicated to my mom, Kathy, and boyfriend, Devin. Thank you both for your unconditional love and encouragement as I navigate my academic career.

N.M.H. 


\section{CONTENTS}

Page

ACKNOWLEDGMENTS $\quad$ i

CONTENTS

TABLES $\quad \mathrm{V}$

FIGURES vi

CHAPTER

I. INTRODUCTION 1

II. REVIEW OF THE LITERATURE 4

Motivation in Romantic Relationships $\quad 4$

Social Motives and Goals $\quad 6$

The Benefits of Self-Expansion for

Maintaining Romantic Relationships $\quad 8$

The Role of Self-Expansion in Relationship

Initiation $\quad 10$

$\begin{array}{ll}\text { Overview of the Current Research } & 14\end{array}$

$\begin{array}{lll}\text { III. } & \text { PURPOSE OF STUDY } 1 & 17\end{array}$

IV. STUDY 1: METHOD 21

$\begin{array}{ll}\text { Participants } & 21\end{array}$

Design 21

Procedure $\quad 22$

Pre-Vignette Measures $\quad 22$

Approach and avoidance motivation $\quad 22$

$\begin{array}{ll}\text { Curiosity } & 23\end{array}$

Self-Expansion Opportunity Vignette $\quad 23$ 
$\begin{array}{ll}\text { Post-Vignette Measures } & 24\end{array}$

Romantic liking 24

Self-expansion desire $\quad 25$

General perceived compatibility 25

General perceived similarity $\quad 26$

Demographics 26

V. RESULTS AND DISCUSSION OF STUDY 1 27

Preliminary Analyses $\quad 27$

Tests of Hypotheses and Research Questions 29

Hypothesis 1a $\quad 29$

Hypothesis $1 \mathrm{~b} \quad 31$

Hypothesis 1c $\quad 32$

Hypothesis 1d 36

Hypothesis $2 \quad 37$

$\begin{array}{ll}\text { VI. PURPOSE OF STUDY } 2 & 40\end{array}$

VII. STUDY 2: METHOD 44

$\begin{array}{ll}\text { Participants } & 44\end{array}$

Procedure $\quad 45$

Pre-Interaction Measures 46

Approach and avoidance motivation $\quad 46$

$\begin{array}{ll}\text { Curiosity } & 47\end{array}$

Desire for social intimacy 47

$\begin{array}{ll}\text { Post-Interaction Measures } & 47\end{array}$

$\begin{array}{ll}\text { Partner's attractiveness } & 47\end{array}$

Romantic liking $\quad 48$

Perceived self-expansion opportunity $\quad 48$

General perceived compatibility $\quad 48$

General perceived similarity $\quad 49$

Closeness $\quad 49$

Desire to contact partner $\quad 49$

Demographics $\quad 49$

VIII. RESULTS AND DISCUSSION OF STUDY 2

$\begin{array}{ll}\text { Analytic Strategy } & 50\end{array}$ 
Preliminary Analyses $\quad 50$

Tests of Hypotheses and Research Questions 52

Hypothesis $1 \quad 52$

Hypothesis $2 \quad 54$

Exploratory question $1 \quad 54$

Exploratory question $2 \quad 56$

$\begin{array}{lll}\text { IX. GENERAL DISCUSSION } & 60\end{array}$

Strengths, Limitations, and Future Directions 65

$\begin{array}{ll}\text { Conclusions } & 67\end{array}$

$\begin{array}{lc}\text { REFERENCES } & 68\end{array}$

APPENDIX: Question Sets for Social Interaction Task 75 


\section{TABLES}

Table $\quad$ Page

1. Correlation Matrix, Means, and Standard Deviations for Study 1

2. Means and Standard Deviations for the Four Attraction Variables 37

3. Means and Standard Deviations for the Four Attraction Variables by Level and Type of Self-Expansion Opportunity 39

4. Correlation Matrix, Means, and Standard Deviations for Study 2

5. Fixed Effects for Approach Motivation as a Moderator of the Relation between Self-Expansion Opportunity and Romantic Liking 53

6. Estimates of Fixed Effects for Curiosity as a Moderator of the Relation between Self-Expansion Opportunity and Romantic Liking 55

7. Hierarchical Regression Analysis for Romantic Liking 57

8. Hierarchical Regression Analysis for Participants' Desire to Contact their Partner 


\section{FIGURES}

$\begin{array}{ll}\text { Figure } & \text { Page }\end{array}$

1. Interaction of Approach Motivation x Level of Self-Expansion Opportunity on Romantic Liking

2. Interaction of Approach Motivation x Level of Self-Expansion Opportunities on Self-Expansion Desire 


\section{CHAPTER I}

\section{INTRODUCTION}

Acquiring and maintaining close relationships is a central human motivation (Baumeister \& Leary, 1995). People navigate their relationships with the influence of several core motivational systems that stem from their need for social belongingness and interdependence (Reis, Collins, \& Berscheid, 2000). Research on life satisfaction and subjective well-being consistently reveal interpersonal relationships as a necessity for happiness (Diener \& Seligman, 2002). Thus, further research is warranted to investigate the connection between people's motivations, including the needs to belong and to grow, and their ability to form lasting interpersonal relationships.

One type of motivation that may affect personal relationships is self-expansion motivation. Self-expansion, the motivation for people to learn, explore, and grow, is facilitated by novel and challenging activities, often with close others (Aron \& Aron, 1986; Aron, Paris, \& Aron, 1995). The opportunities for people to engage in activity with others, and share tangible and social resources, typically result in inclusion of others into the self, or overlap in their self-concepts (Aron \& Aron, 1986). The process of relationship initiation itself is a novel experience and highly desirable to many individuals (Amodio \& Showers, 2005). Likewise, the self-expansion process is important for relationship formation because of its intimacy-enhancing qualities (Aron, Aron, \& Norman, 2001). The focus of the present research is on the role of self- 
expansion motivation in the relationship initiation phase, specifically, how people's desires to self-expand influence their attraction to others, in combination with their evaluations of potential partners' resources, or self-expansion opportunity.

Of particular interest is the notion that some people have greater self-expansion motivation than others. These individual differences in self-expansion motivation are likely to influence individuals' attraction to others and affect with whom they pursue relationships. For example, Mattingly, McIntyre, and Lewandowski (2012) found that individuals who were high in approach motivation liked potential partners with greater self-expansion opportunity more than potential partners with less self-expansion opportunity. In contrast, individuals low in approach motivation placed less value on expansion opportunity in mate preferences. For some people, self-expansion motivation may be especially salient, making their choice for an ideal partner someone who can provide the greatest expansion opportunity.

Aron and Aron (1986) posit that people should want to initiate relationships with individuals dissimilar to themselves, who provide them with the greatest opportunity for self-expansion, if they could be assured of being liked by them. This contradicts one of the most robust findings in the attraction literature, the similarity-attraction effect (Byrne, 1997). However, research has found that similarity is not as central to attraction as once believed (for review, see Montoya, Horton, \& Kirchner, 2008). Several studies reveal that the desirability of actual similarity dissipates as individuals interact for greater lengths of time (Sunnafrank, 1983; Sunnafrank \& Miller, 1981; Tidwell, Eastwick, \& Finkel, 2013). The juxtaposition of similarity and dissimilarity in the attraction literature warrants future 
research on the roles of self-expansion motives and self-expansion opportunity in attraction.

The review of relevant literature below will first begin with an overview of the important findings that have shaped human motivation research with respect to romantic relationship initiation and maintenance. Second, I will review the literature of approach motivation and trait curiosity, two concepts that are theoretically and empirically linked to self-expansion and likely to influence partner selection. Third, I will discuss the benefits of self-expansion opportunity in existing relationships and how self-expansion relates to attraction and relationship initiation. Lastly, I will state the purposes of the two studies in my thesis and explain in detail my hypotheses and research questions. 


\section{CHAPTER II}

\section{REVIEW OF THE LITERATURE}

\section{Motivation in Romantic Relationships}

People have self-related motives and emotions for the purposes of enhancing social interaction and facilitating relationship development (Leary, 2007). Past research has found motivation to play an especially important role in close relationships (Blais, Sabourin, Boucher, \& Vallerand, 1990). Specifically, motivation is at the core of partner selection, relationship development, and relationship maintenance behaviors (McAdams, 1984; Pittman \& Heller, 1987; Rempel, Holmes, \& Zanna, 1985; Seligman, Fazio, \& Zanna, 1980 as cited in Blais et al., 1990).

Human motivation guides individuals' personal and social goals. One early theory of motivation is Maslow's (1970) hierarchy of needs, proposing that people have fundamental needs for fulfillment that are met through positive regard and selfactualization. Self-actualization, the desire to reach one's full potential, is composed of various cognitive needs such as the ability to explore, create, and learn. Similarly, Fredrickson's (2004) broaden-and-build theory posits the ability of positive emotions to broaden people's cognitive capabilities and build their personal resources. Such positive emotions are linked to increased attention, creativity, and desire to learn (Isen, 2000).

Romantic relationships are often studied from a growth perspective. Maslow (1970) proposed that individuals seek to fulfill their needs through their relationships 
with others. There are several prominent theories of growth motivation (Knee, 1998; Knee, Nanayakkara, Vietor, Neighbors, \& Patrick, 2001; Knee, Patrick, Vietor, Nanayakkara, \& Neighbors, 2002). One such theory refers to implicit theories, which are described as personal beliefs that individuals hold about relationships, like scripts or schemas. Knee and colleagues (Knee, 1998; Knee et al., 2001; Knee et al., 2002) classify these beliefs by differentiating between destiny beliefs and growth beliefs. Destiny beliefs are typically described as beliefs that an individual is meant to be with his or her partner and the fate of the relationship is not in his or her hands. In contrast, individuals with growth beliefs maintain that relationships take time to develop and view challenges as opportunities to learn from and expand their views. Knee and colleagues (Knee, 1998; Knee et al., 2001; Knee et al., 2002) suggest that these implicit beliefs about relationships guide individuals' relationships in the form of motivations.

Deci and Ryan's $(1985 ; 1991)$ self-determination theory is a growth theory that suggests that people possess three primary psychological needs: feelings of competency, autonomy, and relatedness. When assessing existing romantic relationships, researchers have found that multiple measures of couples' self-determined motivation (i.e., intrinsic motivation, integrated regulation, and identified regulation) are positively correlated with relationship quality (Blais et al., 1990). Specifically, self-determined motivation is associated with individuals' reports of greater interest (Ryan, Mims, \& Koestner, 1983), positive affectivity (Rempel et al., 1985; Seligman et al., 1980), creativity (Amabile, 1983), and spontaneity (Koestner, Ryan, Bernieri, \& Holt, 1984) as discussed by Blais et al. (1990). Individuals who are self-determined also show greater openness to learning 
and growth from their relationship-related experiences (Blais et al., 1990). In particular, Hodgins and Knee (2002) suggested that growth-oriented individuals may view relationship problems as opportunities to learn about their partner and grow closer.

As discussed previously, self-expansion occurs when individuals engage in novel and exciting experiences that may occur either independently or through their relationships with others (Aron \& Aron, 1986; Gordon \& Baucom, 2009). The selfexpansion model posits that self-expansion, which is facilitated by novel and arousing activities, is attained through access to other's resources and influences inclusion of that other into the self (Aron \& Aron, 1986; 1996; Aron et al., 1995). These descriptions suggest that self-expansion motivation may stem from people's most basic psychological needs and motivations for belongingness. Ultimately, self-expansion motivation can be explained from the perspective of theories of approach motivation and growth motivation.

\section{Social Motives and Goals}

Approach motives and goals have been theoretically and empirically linked to the study of self-expansion motivation. In fact, Mattingly et al. (2012) presented the argument that descriptors of approach motivation (e.g., gain, grow, and striving; Gray, 1987) overlap closely with those used to describe self-expansion motivation (e.g., expand, seek, and enhance; Aron et al., 2001). Approach social goals, as described in Gable's (2006) model of social motivation, are motives for positive relationship-related experiences (e.g., growth, enjoyment). Related to approach social goals are avoidance social goals, which are motives to avoid negative experiences (e.g., conflict, rejection). 
Approach social goals are related to numerous positive personal and relational outcomes such as subjective well-being (Elliot, Gable, \& Mapes, 2006), relationship quality (Impett, Gable, \& Peplau, 2005a; Impett et al., 2010; Impett, Peplau, \& Gable, 2005b), and sexual desire (Impett, Strachman, Finkel, \& Gable, 2008). An inclination towards avoidance goals is associated with physical health symptoms (Elliot et al., 2006), lower relationship quality (Impett et al., 2010), and less partner responsiveness (Impett et al., 2010).

Gable's (2006) model suggests that individuals' dispositional approach and avoidance tendencies and their environment combine to uniquely influence social goals. Approach goals should not be considered in opposition to avoidance goals; instead, Gable, Reis, and Elliot (2003) indicate that these motives occur independently of one another. Approach motivation, but not avoidance motivation, positively influences many aspects of romantic relationships, from relationship initiation to relationship maintenance (Mattingly et al., 2012).

In a similar vein, trait curiosity, described by researchers as the propensity to learn, explore, and immerse oneself in activity, is a third concept that can be conceptually linked to both approach motivation and self-expansion motivation (Kashdan, Rose, \& Fincham, 2004). Robust evidence suggests that curiosity influences relationship initiation by enhancing positive affect, intimacy, and perceptions of responsiveness from others (Kashdan, McKnight, Fincham, \& Rose, 2011; Kashdan \& Roberts, 2004; 2006). Empirically, approach motivation has been positively linked to trait curiosity (Kashdan et al., 2004). Likewise, researchers have found a positive association between perceptions 
of self-expansion opportunity (Self-Expansion Questionnaire; SEQ) and approach motivation (relationship-specific and general) but not avoidance motivation (Mattingly et al., 2012; Study $1 \& 2$ b). Finally, all three of these concepts are correlated with positive affect and various measures of relationship quality (Agnew, Van Lange, Rusbult, \& Langston, 1998; Aron, Norman, Aron, McKenna, \& Heyman, 2000; Carver \& White, 1994; Graham, 2008; Impett et al., 2005a; Kashdan et al., 2004; Mattingly \& Clark, 2012; Mattingly et al., 2012; Neff \& Harter, 2002; Reissman, Aron, \& Bergen, 1993).

\section{The Benefits of Self-Expansion for Maintaining Romantic Relationships}

Self-expansion theory has been used as a theoretical framework to investigate many stages of romantic relationships from initiation to dissolution (Aron et al., 2001). Most notable in the literature is the influence that self-expansion motivation has on existing relationships, however, very little research has been conducted to test the effect of self-expansion motivation in relation to relationship initiation. Although my study focuses on the role of self-expansion motivation and self-expansion opportunities in the initiation of relationships, I present a review of this literature because of its relevance to why people may desire to enter self-expanding relationships.

Researchers have observed numerous connections between couples' shared experiences of self-expanding activities and their later reports of relationship quality. In particular, Aron and colleagues (2000) surveyed a community sample of individuals through a local newspaper to assess the influence of self-expansion on relationship quality. They found correlational support for the mediating effect that relational boredom has on the association between participation in novel/exciting shared-activities and 
relationship quality. Specifically, Aron et al. (2000) reported that relational boredom was negatively related to participation in self-expanding activities and relationship quality. A subsequent study was conducted where couples came into the laboratory and were randomly assigned to participate in novel/exciting, mundane, or no activity. Again, Aron et al. (2000) found that couples who participated in the novel/exciting activity perceived their relationship quality as higher than those who participated in the other types of activity.

In a similar vein, a robust finding is that it is not just how much time couples spend together but how they spend their time that matters (Graham, 2008). Specifically, Graham (2008) used Experience Sampling Method procedures to study 20 cohabitating couples for one week and collected random reports of the couples' shared activities and the degree of felt self-expansion. Participants described their mood on various rating scales (e.g., excited to bored, involved to detached) to indicate the degree of selfexpansion they felt during various experiences. More frequent feelings of self-expansion were associated with higher ratings of relationship quality.

Several longitudinal studies have yielded similar results, indicating that selfexpansion activity is an ideal strategy for relationship maintenance. For example, Reissman and colleagues (1993) asked couples to participate in activities deemed “exciting," "pleasant," or their normal activity for 10 weeks. Individuals who were asked to participate in exciting activities for 1.5 hours a week reported higher relationship quality at the end of the 10 weeks than those in the pleasant activities group. Similarly, Carson, Carson, Gil, and Baucom (2007) found that couples' participation in a 
mindfulness intervention significantly enhanced the quality of time that they spent together, such that couples reported engaging in more exciting, self-expanding activities together.

Finally, self-expansion opportunity has been negatively linked to boredom in relationships, and boredom has been characterized as the product of low approach motivation and positive emotions (Strong, Fincham, \& Aron, 2009). Tsapelas, Aron, and Orbuch (2009) investigated the effect of self-expansion opportunities on marriage and found that relationship boredom was negatively related to satisfaction and led to less satisfaction nine years later (participants were surveyed at their $7^{\text {th }}$ and $16^{\text {th }}$ years of marriage). These studies provide evidence that self-expansion opportunity and (shared) self-expansion activities are powerful relationship maintenance tools to be used for increased relationship quality and longevity.

\section{The Role of Self-Expansion in Relationship Initiation}

Unfortunately, much less is known about how self-expansion motivation and opportunity affect mate selection and relationship initiation. Relationship initiation is an exploratory phase marked by rapid exposure to new perspectives, knowledge, and activities (Amodio \& Showers, 2005). As a relationship progresses, individuals begin to include their partner's perspectives and hobbies into their own self-concept (Aron et al., 1995). In their study, Aron and colleagues (1995) asked participants to answer the question "Who are you today?" every few weeks and found that individuals in a developing relationship wrote more self-descriptors over the course of the semester. Similarly, Waugh and Fredrickson (2006) found that positive emotions accelerated the 
process of self-expansion as seen in participants' self-concept overlap and understanding with their freshman roommates. Research indicates that individuals expand their selfconcept as they form new relationships (Aron et al., 2005; Aron et al., 1995). However, there has been little research on how self-expansion motivation influences mate selection in the first place, prior to the decision to pursue a relationship.

Slotter and Gardner (2009) have also looked at immediate self-concept change as a function of romantic motivation. Participants first completed a personality traits task to identify how representative each item (e.g., athletic, artistic, studious) was of the self. Afterwards, the participants viewed an online profile of a potential partner of the opposite sex in a romantic context (university dating service) or a non-romantic context (job finding service) followed by measures of liking, similarity, and self-other integration. The profiles used in this study were tailored to the specific participant, such that each contained one trait that was listed as very uncharacteristic of the self along with three moderately corresponding traits. After viewing one of two profiles, participants again rated the representativeness of each of the personality traits for the self. The researchers found that original ratings of low representativeness for specific personality traits were rated as more representative of the self after participants viewed a profile in a romantic context. Such findings reveal that rapid inclusion of other's self-concept into the self immediately closes the gap in trait dissimilarity between potential partners.

In the self-expansion literature, dissimilarity is often synonymous with the availability of novel opportunities from which individuals may learn, grow, or expand. Research by Aron, Steele, Kashdan, and Perez (2006) indicated that the similarity- 
attraction association was contingent on relationship certainty within a bogus-stranger paradigm. Aron et al. (2006) informed participants that they matched them with a samesex student either at random or because they were likely to get along with one another based on personality and interest information. Additionally, the researchers provided each participant with a personalized list of interests from the "matched student" that was similar or dissimilar to those written by the participant in the first session. Aron et al. (2006) found that on the one hand, when male participants were led to believe that the potential friendship was uncertain, they were more interested in befriending similar rather than dissimilar students. On the other hand, when male participants were told that the success of the friendship was likely, they rated greater liking toward dissimilar students. This effect was not found to be significant for female participants. Their research suggests that cues of relationship certainty dissipate the need for individuals to initiate relationships with highly similar others, which leads to greater opportunities for selfexpansion.

More recently, Mattingly et al. (2012) sought to disentangle the influence of approach motivation on romantic relationships. Across three studies, Mattingly et al. conducted correlational research that linked approach motivation (general and relationship-specific) and promotion focus (regulation focus theory) to the amount of self-expansion that occurs in the context of one's existing relationship. Study 1 revealed that romantic partners with greater relationship-specific approach motivation reported experiencing greater self-expansion with their romantic partner than those who were low in approach motives. Likewise, in Studies 2a and 2b, they found that global approach 
motivation and promotion focus, but not avoidance motivation and prevention focus, were positively associated with self-expansion opportunity.

In their Study 3, which is most relevant to my research, Mattingly et al. (2012) utilized a vignette to investigate how romantically unattached individuals' approach motivation and manipulation for opportunities that a potential partner may offer interact to influence romantic liking. Individuals completed an assessment of approach and avoidance motivations before being randomly assigned to read a hypothetical scenario that depicted an initial interaction with an opposite-sex stranger. The vignettes differed in the level of self-expansion opportunity that a potential partner offered [high/low]:

"Imagine you are at a social gathering and you meet someone of the opposite sex you have never met before. In your conversation with this person, you realize that this person is knowledgeable about [several topics that you don't know much about/the same topics that you know much about]. From your conversation, you gather that this person possesses several skills and abilities that you [could potentially learn/already possess]. You feel that together you and this person would have experiences that are [new and challenging/dull and boring]” (p. 8). Individuals high in approach motivation reported greater liking for potential partners with high expansion opportunity, whereas individuals low in approach motivation placed less value on expansion opportunity shown by similar ratings for high and low opportunity targets. According to Mattingly et al. (2012), "approach motivation is only associated with self-expansion if the partner's traits or resources are perceived to be distinct from the individual's attributes, and therefore a self-concept gain is possible" (p. 13). 
However, it is possible that the effects found in their study were due to the negative affective wording in their scenario for low self-expansion opportunities, which described future experiences with a potential partner as "dull and boring." One of the purposes of my Study 1 is to examine this possibility, as will be described in detail below.

\section{Overview of the Current Research}

A gap in the literature exists for the influence of self-expansion motivation in relationship initiation. The current research was designed to test the generalizability of Mattingly et al.'s (2012) research with a replication study and in a live context with people who have the potential to form a real romantic bond. The current research was also designed to bridge existing measures of motivation for a more comprehensive assessment of self-expansion motivation.

The main objective of Study 1 was to replicate Mattingly et al.'s (2012) vignette experiment on self-expansion opportunity with a very important difference. Instead of describing the low opportunity for self-expansion as they had, Study 1 replicated this research and included an affect-neutral alternative, "familiar and comfortable." I also chose to differentiate between two potential types of self-expansion opportunity: selfexpansion due to participation in novel activities and self-expansion due to increased knowledge. Past research has focused almost exclusively on the role that activities play in self-expansion opportunity, rarely assessing the influence of knowledge as a type of selfexpansion opportunity (e.g., Aron et al., 2000; Graham, 2008; Lewandowski \& Aron, 2004; Reissman et al., 1993). Interestingly, Mattingly et al.'s (2012) vignettes focused on knowledge. The interaction between level of self-expansion opportunity and approach 
motivation on liking found by Mattingly et al. could be limited to the type of selfexpansion opportunity, and/or the finding could be an artifact due to the negativity of the wording of the low self-expansion opportunity.

Whereas Study 1 utilized vignettes, Study 2 is designed to investigate the associations among self-expansion motivation, perceived self-expansion opportunities, and romantic liking with a social-interaction paradigm. Study 2 involves pairs of heterosexual, opposite-sex strangers getting acquainted with one another followed by individual assessments of the interaction. In a live-interaction study, opportunity for selfexpansion cannot be manipulated because it is a subjective opinion; therefore I chose to use a correlational design. This study utilized the social-interaction paradigm (also called the "live-interaction" and "get-acquainted interaction paradigm") to examine the role of self-expansion motivation in the context of relationship initiation.

Researchers are gaining access to a more accurate portrayal of relationship initiation and attraction through live interaction studies (Reis, Maniaci, Caprariello, Eastwick, \& Finkel, 2011; Sprecher, Treger, \& Wondra, 2013; Sprecher, Treger, Wondra, Hilaire, \& Wallpe, 2013). This method is typically used in a controlled laboratory study, where researchers can measure a number of variables before and after dyads interact. The social-interaction paradigm is an excellent resource for researchers interested in studying relationship initiation because it provides greater ecological validity than most methods. Additionally, it is important for relationship researchers to capture the relationship initiation process in a more natural context, while still maintaining experimental control. The social interaction paradigm has been successfully used in a number of studies to 
assess different aspects of relationship development (Kashdan et al., 2011; Reis et al., 2011; Sprecher et al., 2013a; Sprecher et al., 2013b).

The social interaction paradigm is an important methodological tool for a number of reasons. When two people first meet, it is not uncommon that they share just a brief initial encounter before deciding whether or not they would like to see each other again (Bredow, Cate, \& Huston, 2008). Social interaction studies provide a brief interaction between two strangers - or a "thin slice" of relationship initiation (Albright, Kenny, \& Malloy, 1988; Ambady \& Rosenthal, 1993; Eastwick \& Finkel, 2008). Researchers frequently manipulate aspects of participants' interactions (e.g., degree of self-disclosure) within the social interaction paradigm to examine how different predictors affect ratings of closeness and liking (Aron, Melinat, Aron, Vallone, \& Bator, 1997; Page-Gould, Mendoza-Denton, \& Tropp, 2008; Sedikides, Campbell, Reeder, \& Elliot, 1999).

A secondary and theoretically driven goal of Study 2 is to examine the relationship between the constructs of approach motivation and curiosity. Currently, there is not a specific measure of self-expansion motivation available in the literature. To resolve this problem, I am measuring approach motivation, curiosity, and a behavioral measure of desire for social intimacy (all measured prior to the interaction) to triangulate existing measures that are theoretically linked to self-expansion motivation. If approach motivation, curiosity, and desire for social intimacy are as empirically linked as they are theoretically, I expect that they will have a similar positive influence on romantic liking. 


\section{CHAPTER III}

\section{PURPOSE OF STUDY 1}

My first study was designed to investigate how various levels of self-expansion opportunity (high, low [neutral], low [negative]) and types of self-expansion opportunity that a potential partner may offer (knowledge vs. activity) relate to individuals' selfexpansion motivation (i.e., approach motivation) and liking for a potential partner. To do so, five vignettes were developed to portray a potential dating partner who differed in the level and type of self-expansion opportunity that they had to offer. The three levels of self-expansion opportunity were operationalized as high (i.e., new and exciting), low (neutral) (i.e., familiar and comfortable), and low (negative) (i.e., dull and boring). To investigate the effects of these variables on different indicators of attraction (i.e., romantic liking, self-expansion desire, perceived compatibility, and perceived similarity), I modified several hypothetical scenarios that were originally designed by Mattingly et al. (2012) to incorporate multiple levels of self-expansion opportunity and types of selfexpansion opportunity. There are three main purposes of the current study.

The first purpose of Study 1 is to replicate Mattingly et al.'s (2012) study with affect-neutral wording for the lower level of expansion opportunity. The hypotheses focused on replicating Mattingly et al. are the following: 
Hypothesis 1a: Participants who view the high self-expansion opportunity vignette will report greater romantic liking, self-expansion desire, and perceived compatibility but less perceived similarity for the potential partner compared to those who view the low self-expansion opportunity vignette that was expressed negatively (low [negative] condition).

Hypothesis $1 b$ : Participants' self-reported approach motivation and trait curiosity are expected to positively relate to their romantic liking, self-expansion desire, perceived compatibility and perceived similarity for the potential partner. Specifically, participants who are high in approach motivation will report greater liking for the potential partner than those who are low in approach motivation. Hypothesis 1c: As in Mattingly et al. (2012), approach motivation will moderate the association between level of self-expansion opportunity and romantic liking, while controlling for avoidance motivation. Specifically, for individuals who imagine a potential partner with low self-expansion opportunities (low [negative] condition), those who are high in approach motivation will report significantly lower romantic liking toward the potential partner than those who are low in approach motivation. In contrast, for individuals who imagine a potential partner with high self-expansion opportunities, those who are high in approach motivation will report greater romantic liking than those low in approach motivation. This pattern will be the same when using self-expansion desire as the criterion. Perceived compatibility and similarity were not assessed because these variables were not discussed in Mattingly et al.'s original study. 
Hypothesis $1 d$ : The disordinal interaction between self-expansion opportunity and approach motivation on romantic liking and self-expansion desire found by Mattingly et al. (2012) was the result of using negative, rather than neutral, descriptors for low self-expansion opportunities. Thus, I predict that (a) participants will report greater liking and self-expansion desire for the target in the high self-expansion opportunity vignette than for the target in either of the low opportunity vignettes and (b) participants will report less liking for the low (negative) vignette than in the low (neutral) vignette.

Hypotheses 1c and 1d did not take into account perceived compatibility or perceived similarity as these variables were not originally tested by Mattingly et al. (2012).

The second purpose of this study is to identify whether there is a difference in romantic liking and self-expansion desire based on whether the type of self-expanding opportunities offered by a potential partner are knowledge-based or activity-based. Mattingly et al. (2012) used knowledge as the primary type of self-expansion in their study, but the bulk of the literature considers self-expansion opportunity to be activity based (e.g., Aron et al., 2000; Graham, 2008; Lewandowski \& Aron, 2004; Reissman et al., 1993) and, as mentioned previously, most of the research on relationship maintenance focuses on shared activities. In the current study, participants were asked to imagine either high or low self-expansion opportunity, where self-expansion opportunity was operationalized by either (a) new knowledge to be learned or (b) new activities available. A direct comparison of the effects of type of self-expansion opportunity has not been 
previously examined in this way. It is possible that individuals' desire for self-expansion opportunity is unique to particular types of expanding activities (e.g., surfing, sewing, reading). Do different types of self-expansion opportunity (activity vs. knowledge) as described in the vignettes, influence romantic liking, self-expansion desire, and perceived similarity? I would presume that self-expansion opportunities focused on activities will produce more liking in a college sample, compared to self-expansion opportunities focused on knowledge, because young adults seem to focus on engaging in leisure and social activities (Larson \& Verma, 1999). My second hypothesis for the current study is:

Hypothesis 2: Individuals who view vignettes describing the type of selfexpansion opportunity as involving activities with the target will report greater romantic liking, self-expansion desire, perceived compatibility, and perceived similarity compared to individuals who view vignettes describing the type of selfexpansion opportunity as involving knowledge gained from the target.

The third purpose of this study is to explore the potential interactions among variables if the two types of self-expansion opportunity are found, as predicted above, to differently affect romantic liking.

Research Question 1: If type of self-expansion opportunity (activity vs. knowledge) influences romantic liking, do level of self-expansion opportunity, type of self-expansion, and approach motivation interact to influence romantic liking, self-expansion desire, and perceived similarity? 


\section{CHAPTER IV \\ STUDY 1: METHOD}

\section{Participants}

Two hundred and twenty-six university students from Illinois State University participated in this study. Of these participants, $149(66.8 \%)$ were female (3 did not report gender). The participants ranged in age from 18 to 39, with a mean age of 21.03 $(S D=2.34)$. A majority of the participants were White/European $(77 \%)$, followed by Black/African-American (11.5\%), Hispanic/Latino/Spanish (5.3\%), Eastern/Asian (.4\%), or Multiracial or undisclosed (4\%). Nine percent of the participants were freshman, 18\% of the participants were sophomores, $36 \%$ of the participants were juniors, $35 \%$ of the participants were seniors, and $1 \%$ of the participants reported being of another academic status. Participants were recruited in sociology and psychology classrooms. Each participant received extra credit for participation in this experiment.

\section{Design}

Study 1 used an experimental design to investigate the influence of self-expansion opportunity and approach motivation on relationship initiation. This study was a $2 \times 2$ factorial between-subjects design with an additional cell representing a control group. Factor one was the level of self-expansion opportunity offered by a potential partner (high vs. low [neutral]). Factor two was the type of self-expansion opportunity offered by a potential partner (knowledge vs. activity). The control condition depicted a potential 
partner who offers a low level of self-expansion opportunity that is negatively stated (low [negative]), and knowledge as the type of self-expansion opportunity. This condition is original to Mattingly et al.'s (2012) study and is necessary for testing hypothesis 1c.

\section{Procedure}

Solicitation for participants took place in select psychology and sociology classrooms. Participants received a questionnaire packet with the informed consent form on the first page. Participants provided implied consent by beginning the questionnaire. In the questionnaire, participants first completed measures for several personal variables. Then, participants received one of the five randomly assigned versions of the hypothetical scenario. After reading the scenario, participants were instructed to provide feedback based on the imagined situation. Finally, participants were debriefed and thanked for their assistance in the current research study.

\section{Pre-Vignette Measures}

Prior to reading the vignette, the participants responded to measures of several individual characteristics.

\section{Approach and avoidance motivation}

I assessed approach and avoidance motivations using the 24-item Behavioral Inhibition System and Behavioral Activation System scales (BIS/BAS; Carver \& White, 1994). Approach motivation (BAS) was measured with 13 items that compose three subscales (BAS Drive, BAS Fun Seeking, and BAS Reward Responsiveness), and consisted of items such as "I will often do things for no other reason than that they might be fun." 
Avoidance motivation (BIS) was measured with 7 items, for example, "I feel pretty worried or upset when I think or know somebody is angry at me." An additional 4 items were included in the BIS/BAS measure as fillers. Both scales elicit responses on a 4-point scale, $(1=$ very false for me, $4=$ very true for $m e)$, which were reversed to indicate higher scores as greater approach or avoidance motivations. The current study showed adequate reliability for the two scales (approach, $\alpha=.83$; avoidance, $\alpha=.77$ ).

\section{Curiosity}

The Curiosity and Exploration Inventory-II assessed two components of trait curiosity: stretching and embracing (CEI-II; Kashdan et al., 2009). The 5-item Stretching subscale examines desire to pursue interesting information and activities. The 5-item Embracing subscale identifies individuals' ability to easily adapt to uncertain and novel experiences. Sample items are "I actively seek as much information as I can in new situations" and "Everywhere I go, I am out looking for new things or experiences," 1 = very slightly or not at all; $2=$ a little; $3=$ moderately; $4=$ quite a bit $; 5=$ extremely. I found adequate reliability for these subscales; CEI-II: Stretching, $\alpha=.78$; CEI-II: Embracing, $\alpha=.75$ (total $\alpha=.89$ ).

\section{Self-Expansion Opportunity Vignette}

Five vignettes were created based on Mattingly et al.'s (2012) Study 3 manipulation. The vignettes differed based on self-expansion opportunity (high vs. low [neutral]) and opportunity type (knowledge vs. activity) with the addition of the fifth control vignette (low [negative] with knowledge). Participants received the following instructions: "Please read the following paragraph very carefully. If you are currently 
involved in a romantic relationship, proceed as if you were single. After taking some time to think about this scenario, you will be asked a variety of questions on your thoughts about the imagined situation." After reading these instructions, participants received one of five vignettes. The vignettes differed on the sections emphasized below.

Imagine you are at a social gathering and you meet an attractive (single) person of the opposite $\operatorname{sex}^{1}$ who you have never met before. In your conversation with this person, you realize that this person is [knowledgeable about several topics/interested in several activities] that you [don't know/know] much about. From your conversation, you gather that this person possesses several skills and abilities that you [could potentially learn/already possess]. You feel that together you and this person would have experiences that are [new and challenging/familiar and comfortable/boring and dull].

${ }^{1}$ or same sex if you are gay/lesbian

\section{Post-Vignette Measures}

Participants provided their reactions to the potential partner described in the vignette.

Romantic liking

A 5-item measure developed by Mattingly et al. (2012) was used to assess friendship and romantic attraction toward the target described in the vignette. This scale consisted of items such as: "How interested would you be in going on a date with this person?" $(1=$ not at all interested, 7 = very interested $)$; and "If you started dating, how long do you think the two of you would remain together?" $(1=$ a very short time, $7=a$ very long time). This study indicates good reliability for romantic liking, $\alpha=.90$. 


\section{Self-expansion desire}

Self-expansion desire was measured using a modified version of Lewandowski and Aron's (2002) self-expansion questionnaire. This scale was originally constructed to assess opportunity for self-expansion in an existing romantic relationship and was altered to assess participants' perceptions of self-expansion opportunity with a potential partner. The current study used 9 of the original 14 items to assess self-expansion opportunity because some items were not easily converted when the scale was modified to reflect perceptions of a potential other rather than a current dating partner (i.e., "Do you often learn new things about your partner?"). Sample items included "How much would this person expand your own capabilities?" and "How much would this person provide a source of exciting experiences?" Participants were instructed to rate their perceptions of self-expansion opportunity on a 7-point scale, $1=$ not very much, $7=$ very much. The reliability for self-expansion desire for this study was good, $\alpha=.94$.

\section{General perceived compatibility}

I created this measure to assess individuals' perceptions regarding their ability to get along with the potential partner in the future. The three items designed for this study use a 7-point scale; $1=$ Strongly Disagree, $7=$ Strongly Agree. Items included "This person and I would get along very well in the future," "This person and I seemed to be very compatible," and "This person and I would have a harmonious relationship." This study revealed good reliability for general perceived compatibility, $\alpha=.86$. 


\section{General perceived similarity}

Two items from Tidwell et al.’s (2013) research were modified to assess holistically individuals' perceived similarity to the potential partner. Items included "This person and I seemed to have a lot in common" and "This person and I seemed to have similar personalities." These items were answered on a 7-point scale; $1=$ Strongly

Disagree, 7 = Strongly Agree. This study indicated good reliability for general perceived similarity, $\alpha=.89$.

Demographics

The questionnaire asked participants for their age, gender, ethnic background, year in college, and relationship status. 


\section{CHAPTER V \\ RESULTS AND DISCUSSION OF STUDY 1}

\section{Preliminary Analyses}

Table 1 presents descriptive statistics for the variables measured in Study 1, including means, standard deviations, and intercorrelations among the variables. On average, participants' scores were high for approach and avoidance motivation, averaging $3.18(S D=.40)$ for approach and $3.04(S D=.56)$ for avoidance motivation on a 4-point scale. Individuals were closer to the midpoint of the scale in their curiosity scores with a mean of $3.30(S D=.75)$ on a 5-point scale. Finally, participants' scores were generally high for each of the four dependent variables: romantic liking $(M=5.39)$, self-expansion desire $(M=4.75)$, perceived similarity $(M=5.27)$, and perceived compatibility $(M=$ 5.16) each measured on a 7-point scale.

The three independent variables (i.e., approach motivation, avoidance motivation, and curiosity) were associated as predicted. Consistent with past research (i.e., Carver \& White, 1994), approach and avoidance motivation were not correlated, $r=.08, p=.25$. Additionally, approach motivation and curiosity, two theoretically similar constructs, were strongly correlated, $r=.50, p<.01$. Finally, the association between avoidance motivation and curiosity was moderate and negative $(r=-.25, p<.01)$, suggesting that individuals high in avoidance motivation tend to exhibit less curiosity.

The four dependent variables were generally significantly and positively related. 
Romantic liking was strongly related to self-expansion desire $(r=.68 ; p<.01)$, suggesting that one's desires to self-expand with the target are closely tied with feelings of romantic liking. Romantic liking was also strongly related to perceived compatibility $(r=.61 ; p<.01)$, indicating that individuals report greater liking toward a target whom they perceived as highly compatible. Finally, romantic liking was moderately related to perceived similarity $(r=.34 ; p<.01)$, suggesting that an element of similarity with another is desirable.

Perceived compatibility was moderately related to self-expansion desire $(r=.32$; $p<.01)$. There was a strong relation between perceived similarity and compatibility, such that participants viewed similar others as more compatible and vise versa.

Interestingly, self-expansion desire and perceived similarity were unrelated in this study $(r=-.01, p=.87)$, suggesting that these two constructs are independent of one another. As noted previously, self-expansion is typically operationalized as an opportunity to learn and grow from close others (indicating a trace of dissimilarity), therefore a negative correlation was predicted. 
Table 1

Correlation Matrix, Means, and Standard Deviations for Study 1

\begin{tabular}{llllllll}
\hline Measure & 1 & 2 & 3 & 4 & 5 & 6 & 7 \\
\hline 1. Approach Motivation & -- & & & & & & \\
2. Avoidance Motivation & .08 & -- & & & & & \\
3. Curiosity & $.50^{* *}$ & $-.25^{* *}$ & -- & & & & \\
4. Romantic Liking & $.22^{* *}$ & .06 & $.25^{* *}$ & -- & & & \\
5. Self-Expansion Desire & $.16^{*}$ & .11 & $.26^{* *}$ & $.68^{* *}$ & -- & & \\
6. Perceived Similarity & $.21^{* *}$ & .08 & .10 & $.34^{* *}$ & -.01 & -- & \\
7. Perceived Compatibility & $.31^{* *}$ & .08 & $.24^{* *}$ & $.61^{* *}$ & $.32^{* *}$ & $.62^{* *}$ & -- \\
& & & & & & & \\
$M$ & 3.18 & 3.04 & 3.30 & 5.39 & 4.75 & 5.27 & 5.16 \\
$S D$ & .40 & .56 & .75 & 1.05 & 1.19 & 1.29 & 1.01 \\
Coefficient $a$ & .83 & .77 & .89 & .90 & .94 & .89 & .86 \\
\hline
\end{tabular}

$* p<.05 ; * * p<.01$.

\section{Tests of Hypotheses and Research Questions}

Hypothesis 1 a

Hypothesis 1a predicted that participants viewing the high self-expansion opportunity vignette would report greater romantic liking, self-expansion desire, and perceived compatibility and less perceived similarity for the other than those viewing the low (negative) self-expansion opportunity vignette. This hypothesis was tested by conducting independent samples $t$-tests comparing the two groups for each of the dependent variables. For this hypothesis, only data provided by individuals assigned to the knowledge condition were used, in order to test whether or not the current findings replicate Mattingly et al.'s (2012) original findings.

The first dependent variable assessed was romantic liking. The low (negative) opportunity condition had an average romantic liking score of $4.68(S D=.96)$, whereas the high self-expansion opportunity condition had an average romantic liking score of $5.56(S D=.96)$. These scores were significantly different, $t(89)=-4.39, p<.001, d=.92$, 
such that individuals in the high self-expansion opportunity condition reported greater liking for the potential other than individuals in the low (negative) condition.

The next dependent variable assessed was self-expansion desire. The low (negative) opportunity condition had an average self-expansion desire score of 3.79 ( $S D$ $=.88$ ), whereas the high self-expansion opportunity condition had an average selfexpansion desire score of $5.49(S D=.76)$. These scores were significantly different, $t(91)$ $=-9.97, p<.001, d=2.07$, with individuals in the high self-expansion opportunity condition reporting greater self-expansion desire than those in the low (negative) opportunity condition.

The third dependent variable assessed was perceived compatibility. Participants in the low (negative) opportunity condition had an average perceived compatibility score of $4.93(S D=.97)$, whereas the participants in the high self-expansion opportunity condition had an average perceived compatibility score of $4.97(S D=1.05)$. These scores were not significantly different, $t(90)=-.17, p=.86, d=.04$, revealing that individuals may not attend to self-expansion opportunities when determining their compatibility with another.

The final dependent variable assessed was perceived similarity. Participants in the low (negative) opportunity condition had an average perceived compatibility score of $5.53(S D=1.08)$, whereas the participants in the high self-expansion opportunity condition had an average perceived compatibility score of $4.43(S D=1.20)$. These scores were significantly different, $t(86)=4.54, p<.001, d=.96$, revealing that individuals perceived individuals in the low self-expansion opportunity condition more similarly than those who viewed the high self-expansion opportunity condition. 
Hypothesis 1a was partially supported; individuals generally desire a romantic other who provides many, as opposed to few, opportunities for self-expansion. However, this difference may be magnified as the analyses utilized the low (negative) condition found in Mattingly and colleagues' (2012) original work, which will be examined further in Hypothesis 1d. Contrary to my hypothesis, however, self-expansion opportunity was unrelated to individuals' perceptions of compatibility with the potential target.

\section{Hypothesis $1 b$}

For Hypothesis 1b, I predicted that approach motivation and trait curiosity would positively correlate with ratings of romantic liking, self-expansion desire, and perceived compatibility. The total sample was used to assess this hypothesis. Approach motivation and romantic liking were moderately, positively related, $r(221)=.22, p<.001$; controlling for avoidance did not affect this relation, $\operatorname{pr}(220)=.22, p=.001$. Likewise, trait curiosity and romantic liking were positively associated, $r(216)=.23, p=.001$. Similarly, approach motivation and self-expansion desire were moderately, positively associated, $r(221)=.17, p<.01$; controlling for avoidance did not affect this relation, $p r$ $(220)=.16, p<.01$. Trait curiosity was also positively correlated with self-expansion desire, $r(218)=.25, p<.001$. Next, approach motivation and perceived similarity were positively correlated $r(216)=.21, p<.01$; controlling for avoidance motivation did not affect this relation, $\operatorname{pr}(215)=.18, p<.01$. Similarity and trait curiosity were unrelated, $r$ $(218)=.08, p=.27$. Finally, approach motivation and perceived compatibility were moderately, positively correlated, $r(221)=.31, p<.001$; controlling for avoidance did not affect this relation, $\operatorname{pr}(220)=.30, p<.001$. Likewise, trait curiosity was positive 
associated with perceived compatibility, $r(218)=.21, p<.01$.

These results indicate that hypothesis $1 \mathrm{~b}$ was supported. Individuals' ratings of approach motivation, but not avoidance motivation, positively correlated with several measures of attraction (i.e., romantic liking, self-expansion desire, perceived similarity, and perceived compatibility). These findings replicate those originally found in Mattingly et al.'s (2012) studies of existing romantic couples and unattached individuals rating a potential target. It is possible that approach-oriented individuals have a greater desire for social intimacy, a mechanism that is explored further in Study 2.

\section{Hypothesis $1 c$}

My next hypothesis (1c) predicted a replication of Mattingly et al.’s (2012) findings (approach motivation moderated the link between self-expansion opportunity and romantic liking/self-expansion desire) using hierarchical regression analyses. Only the participants who were in the low (negative) and high self-expansion opportunity conditions who read the knowledge (type of opportunity) vignette were used to test whether Mattingly et al.'s (2012) pattern of findings would replicate. This analysis included approach motivation as a moderator of the relation between level of selfexpansion opportunity and romantic liking, while controlling for avoidance motivation. In the first step of the regression analysis, avoidance motivation, approach motivation, and the level of self-expansion opportunity manipulation explained a significant proportion of variance in romantic liking scores, $F(3,87)=7.24, R^{2}=.20, p<.001$. Of these variables, however, level of self-expansion opportunity was the only significant (unique) predictor of romantic liking; $b=.88, t=4.38, p<.001$; individuals reported 
greater liking for targets said to provide many opportunities for self-expansion than for targets providing few opportunities.

In the second step of the regression analysis, the interaction term between level of self-expansion opportunity and approach motivation significantly improved the variance accounted for in romantic liking, $\Delta R^{2}=.05, \Delta F(1,86)=6.12, p=.02$. Thus, approach motivation was a significant moderator of the relationship between level of selfexpansion opportunity and romantic liking. Simple slopes analyses revealed that individuals high in approach motivation were significantly more likely to report romantic liking toward a target with many opportunities for self-expansion than toward one with few expansion opportunities, $b=1.37, t=4.93, p<.001$ (see Figure 1). In contrast, individuals low in approach motivation did not show preference for one target over the other based on expansion opportunities, $b=.39, t=1.41, p=.16$.
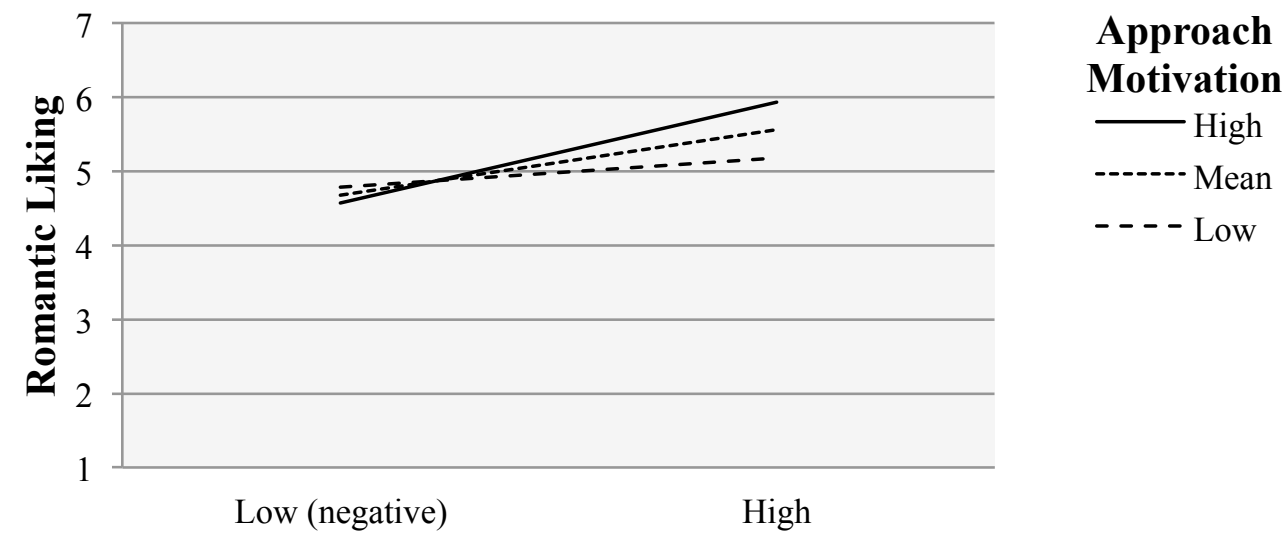

Level of Self-Expansion Opportunity

Figure 1. Interaction of Approach Motivation x Level of Self-Expansion Opportunity on Romantic Liking 
The second part of Hypothesis 1c assessed the moderating role of approach motivation in the relation between level of self-expansion opportunity and self-expansion desire, while controlling for avoidance motivation. In the first step of the regression analysis, avoidance motivation, approach motivation, and the level of self-expansion opportunity manipulation explained a significant proportion of variance in self-expansion desire scores, $F(3,89)=34.31, R^{2}=.54, p<.001$. Level of self-expansion opportunity was the only significant predictor of self-expansion desire; $b=1.68, t=9.92, p<.001$; individuals reported greater desire to self-expand with targets said to provide many opportunities for self-expansion than for targets providing few opportunities.

In the second step of the regression analysis, the interaction term between level of self-expansion opportunity and approach motivation did not improve the model, $\Delta R^{2}=$ $.02, \Delta F(1,88)=3.37, p=.07$. Thus, approach motivation did not moderate the relation between level of self-expansion opportunity and self-expansion desire. 


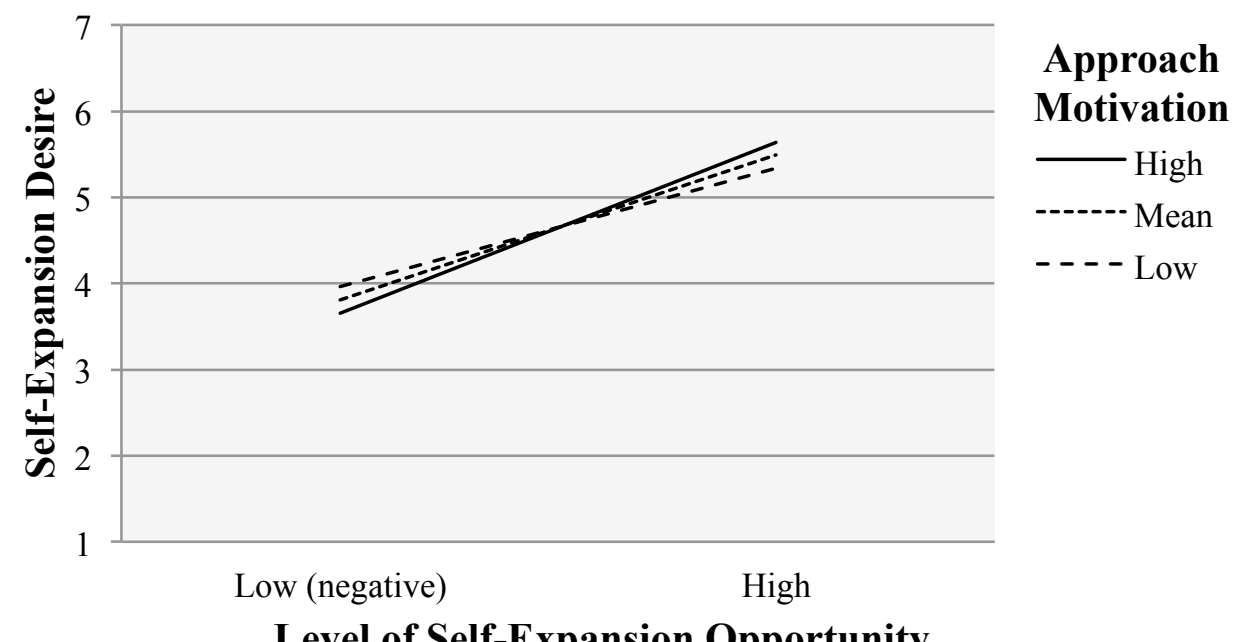

Figure 2. Interaction of Approach Motivation x Level of Self-Expansion Opportunities on Self-Expansion Desire

Hypothesis 1c was a direct replication of the moderation analyses conducted in Mattingly et al. (2012). The first part of this hypothesis was supported, such that approach motivation moderated the relation between self-expansion opportunity and romantic liking. However, my findings diverged slightly from the original study. In Mattingly et al. (2012), individuals reporting low (negative) and high approach orientation rated the target offering high opportunities similarly. In contrast, when presented with the target with fewer opportunities for self-expansion, highly approach oriented individuals rated the target as significantly less liked than those with low approach orientation. In my study, individuals high in approach motivation rated the target offering many opportunities as more likable than individuals with low motivation. The low and high approach-oriented individuals rated the low (negative) condition 
similarly. The second portion of Hypothesis 1c did not support Mattingly et al.'s (2012)

original findings. However, my results indicated a trend in the hypothesized direction that approached significance.

\section{Hypothesis $1 d$}

My next hypothesis predicted that the negative wording used to describe low selfexpansion opportunity in Mattingly et al.'s (2012) vignettes may have skewed their resulting interaction. In particular, I expected that participants would rate the target in the low (negative) self-expansion opportunity condition as liked and with less self-expansion desire than the target in the low (neutral) self-expansion opportunity condition. These conditions differ only on the basis of the negative valence of the last sentence, which suggests that a potential relationship with the target would be "dull and boring" versus "familiar and comfortable." If participants are truly reacting to the low level of selfexpansion opportunity and not the negative wording, than there should not be a significant difference between participants' ratings for the potential partner depicted in the two low self-expansion opportunity conditions.

I conducted two One-way ANOVAs to investigate whether negative affective wording affected individuals' scores for romantic liking and self-expansion desire. Table 2 shows the means and standard deviations for the attraction measures across the three levels of self-expansion opportunity. There was a significant effect of the level of selfexpansion opportunity on romantic liking, $F(2,131)=12.53, p<.001, d=.91$, and selfexpansion desire, $F(2,133)=36.03, p<.001, d=1.56$. Planned contrasts revealed that reading the high expansion opportunity vignette produced greater liking, $t(131)=2.28, p$ 
$=.02$, and self-expansion desire, $t(116.30)=8.52, p<.001$, than reading either of the low opportunity vignettes. Additionally, a second contrast revealed that the low (negative) vignette produced significantly lower ratings of romantic liking, $t(131)=-4.43, p<.001$, and self-expansion desire, $t(75.68)=-3.01, p<.01$, than the low (neutral) vignette.

Table 2

Means and Standard Deviations for the Four Attraction Variables

\begin{tabular}{lccc}
\hline & \multicolumn{3}{c}{ Level of Self-Expansion Opportunity } \\
\cline { 2 - 4 } Attraction Measures & Low (negative) & Low (neutral) & High \\
\hline Self-Expansion Desire & $3.79(0.89)$ & $4.46(1.15)$ & $5.46(0.88)$ \\
Romantic Liking & $4.68(0.96)$ & $5.58(1.03)$ & $5.55(0.97)$ \\
& $n=46$ & $n=43$ & $n=47$ \\
\hline
\end{tabular}

The significant difference found between the low (negative) and the low (neutral) conditions on ratings of romantic liking and self-expansion desire indicate an effect of the negative valence of the phrase "dull and boring." Therefore, there is some evidence that Mattingly et al.'s (2012) operational definition of level of self-expansion opportunity was likely confounded by the valence of the description.

\section{Hypothesis 2}

Finally, I sought to distinguish between the two types of self-expansion (activities vs. knowledge) made available to individuals from a potential dating partner. This hypothesis was addressed by conducting a Multivariate ANOVA where Type and Level of Self-Expansion served as the independent variables and self-expansion desire, 
romantic liking, perceived compatibility, and perceived similarity served as the dependent variables. For this hypothesis, only data provided by individuals assigned to the low (neutral) and high conditions of the Level of Self-Expansion independent variable were included.

Descriptive statistics for the MANOVA can be found in Table 3. The MANOVA revealed that there was no main effect for the types of self-expansion opportunity on overall attraction (i.e., romantic liking, self-expansion desire, perceived similarity, and perceived compatibility), Wilks' $\Lambda=.99, F(4,165)=.06, p=.99, d=.06$. The main effect for level of self-expansion opportunity on overall attraction was significant, Wilks' $\Lambda=.51, F(4,165)=39.78, p<.001, d=1.96$. Finally the interaction between type and level of self-expansion opportunity was nonsignificant, Wilks' $\Lambda=.98, F(4,165)=.70, p$ $=.59, d=.26$. Further, level of self-expansion opportunity explained the most amount of variance in perceived similarity scores (partial $\eta^{2}=.27$ ) followed by self-expansion desire (partial $\eta^{2}=.22$ ), perceived compatibility (partial $\eta^{2}=.06$ ), and romantic liking (partial $\left.\eta^{2}=.00\right)$. 
Table 3

Means and Standard Deviations for the Four Attraction Variables by Level and Type of Self-Expansion Opportunity

\begin{tabular}{lllll}
\hline & \multicolumn{3}{c}{ Level of Self-Expansion Opportunity } \\
\cline { 2 - 5 } Attraction Measures & \multicolumn{2}{c}{ Low (neutral) } & \multicolumn{2}{c}{ High } \\
\cline { 2 - 5 } & Knowledge & Activity & Knowledge & Activity \\
\hline Self-Expansion Desire & $4.41(1.14)$ & $4.44(1.08)$ & $5.49(.78)$ & $5.44(.99)$ \\
Romantic Liking & $5.62(.98)$ & $5.54(.99)$ & $5.57(.96)$ & $5.54(.99)$ \\
Perceived Compatibility & $5.50(.86)$ & $5.47(.82)$ & $4.98(1.07)$ & $5.00(1.11)$ \\
Perceived Similarity & $6.01(.90)$ & $5.77(.88)$ & $4.43(1.20)$ & $4.63(1.39)$ \\
& $n=40$ & $n=43$ & $n=43$ & $n=46$ \\
\hline
\end{tabular}

In Study 1, I sought to distinguish between two types of self-expansion opportunities: those that increase knowledge and those that increase activity. Unfortunately, there was not a significant difference for type of self-expansion among the attraction measures for this manipulation so no further analyses were conducted. This null finding may be attributed to the subtlety of how type of self-expansion was manipulated. Additionally, people may value self-expanding through increased knowledge and access to activity similarly, therefore producing a similar effect on the measures of attraction. 


\section{CHAPTER VI \\ PURPOSE OF STUDY 2}

Study 2 was conducted as a replication of the design of Mattingly et al. (2012) and Study 1, but without a manipulation of self-expansion opportunity and using a liveinteraction paradigm. There were two main purposes for Study 2. The first purpose of Study 2 was to investigate the associations among individuals' self-expansion motivation (i.e., approach motivation), perceptions of an interaction partner's opportunities for selfexpansion, and ratings of romantic liking, perceived compatibility, and perceived similarity. As noted previously, these associations have never been studied with people who have the potential to become romantically involved. Study 2 tests the generalizability of the findings of Mattingly et al. (2012) and Study 1.

As mentioned earlier, there is robust evidence for overlap among self-expansion motivation, approach motivation, and trait curiosity. In past research, self-expansion motivation with a current romantic partner was positively correlated with a number of personality traits and characteristics such as extroversion, openness, trait curiosity, approach motivation, and positive affectivity (Aron et al., 2001; Gordon \& Lou, 2011; Kashdan \& Steger, 2007). Assuming an empirical link between trait curiosity and approach motivation, I was interested in determining whether trait curiosity would moderate the relationship between level of perceived self-expansion opportunity and romantic liking, as approach motivation was hypothesized to relate in Study 1 
(Hypothesis 1c).

This study involved pairs of heterosexual opposite-sex strangers, who were romantically unattached, meeting for the first time in a laboratory setting. Their interaction consisted of taking turns asking and answering questions about themselves that were designed to increase closeness and familiarity with one another's selfexpansion opportunities. Although the study was conducted in the laboratory, there were no experimental manipulations and therefore the study employed a correlational design to investigate the association of self-expansion motivation (i.e., approach motivation and trait curiosity) with romantic liking. As this study involved live interaction between participants, I relied upon individuals' self-reported perceptions of self-expansion opportunity. What constitutes opportunity is a highly subjective opinion.

To capture participants' perceptions of other's self-expansion opportunity, I utilized the get-acquainted paradigm. Sometimes researchers manipulate the type of conversation that participants engage in. For example, in many social interaction studies participants are asked to engage in conversation that enhances intimacy while others engage in more superficial small-talk (Aron et al., 1997; Page-Gould et al., 2008; Sedikides et al., 1999). It may be advantageous for researchers to implement specific instructions for participants' interactions because of the brevity of social interaction studies (the typical interaction within the social interaction study lasts 20-45 minutes). Individuals' participation in brief interactions means that interaction partners might not have time to discuss certain topics that may be of interest. In particular, there may be insufficient time to assess self-expansion opportunities. Therefore, in this social 
interaction study, I influenced the participants' topics of conversation rather than leaving their conversation unstructured, thus increasing the likelihood that participants would disclose information focused on self-expansion opportunities.

An additional feature of Study 2 is that it incorporates the use of a behavioral measure of desire for social intimacy. Because a live-interaction paradigm was used, we can rely on more than self-reports to tap individuals' social motives. Vohs, Mead, and Goode (2006) used this behavioral measure in a study on the influence of being primed to think about money on social motives. In their experiment, participants were told they would be engaging in a social interaction task with a stranger. The researchers had positioned one chair against a wall and another in the center of the room. Participants were asked to retrieve the chair against the wall for their upcoming social interaction. After dismissing the participants, researchers measured the distance between each chair for an implicit measure of desire for social intimacy. In the present study, I operationally defined desire for social intimacy as the distance between the participant's chair and the placement of the chair for the conversation partner.

Below are the hypotheses and exploratory research questions for Study 2:

Hypothesis 1: Individuals' approach motivation will moderate the association between their perception of the partner's self-expansion opportunity and their romantic liking for this other, while controlling for partner's attractiveness and avoidance motivation. Specifically, there will be a strong, positive association between perceived self-expansion opportunity and romantic liking when approach motivation is high. However, there will be no association between perceived self- 
expansion opportunity and romantic liking when approach motivation is low. Hypothesis 2: Measures of individuals' approach motivation and their own trait curiosity will be positively and significantly correlated. Additionally, these measures will negatively correlate with their desire for social intimacy (greater distance $=$ less desire $).$

Exploratory Question 1: Does an individual's trait curiosity moderate the relation between their own ratings of perceived self-expansion opportunity and romantic liking (while holding their perceptions of partner's attractiveness constant)?

Exploratory Question 2: Do individuals' trait curiosity, approach motivation, and self-expansion opportunity combine to influence their own ratings of romantic liking and desire to contact their partner in the future while controlling for their own avoidance motivation and perceptions of partners' attractiveness? 


\section{CHAPTER VII}

\section{STUDY 2: METHOD}

\section{Participants}

This study consisted of 60 mixed-sex dyads, all of whom were college students from Illinois State University at the time of data collection. Based on the sign-up criteria, participants were required to be heterosexual and romantically unattached. However, at the time of the study, $10 \%$ of the sample reported that they were currently in a romantic relationship. Therefore, data from 108 unattached participants were analyzed, but the data from the 12 romantically involved participants were not. The final sample consisted of 108 participants (54 dyads), of which $48 \%$ were female. The participants ranged in age from 18 to 27 , with a mean age of $20.07(S D=1.72)$. A majority of the participants were White/European (71\%), followed by Black/African-American (14\%), Hispanic/Latino/Spanish (9\%), Eastern/Asian (3\%), or Multiracial (3\%). Twenty-nine percent of the participants were freshman, $28 \%$ of the participants were sophomores, $32 \%$ of the participants were juniors, $10 \%$ of the participants were seniors, and two participants did not report their academic status. Participants were recruited using the Psychology department subject pool and received course credit for volunteering to participate in this study. 


\section{Procedure}

Participants signed up for this study and recorded their weekly availability on the psychology participation board, which was used for scheduling their research session. The researcher scheduled one male and one female participant for each session at a mutually available time. Participants were instructed to arrive at separate, predetermined locations at their scheduled time. Upon participants' arrival, they were greeted by a researcher who obtained informed consent and instructed them how to begin the preinteraction questionnaire. The questionnaire, consisting of measures of approach motivation, avoidance motivation, and trait curiosity, was administered via computer through an online survey software, Select Survey (see Measures section for more details).

Next, the experimenters informed each participant that their getting-acquainted interaction was about to begin. Each experimenter told his or her participant that he or she would be leaving the room to retrieve the other person. The participant was asked to move a chair (that was positioned against the wall) to the center of the room near an existing chair for the interaction, while the experimenter was gone. This distance between the chairs was used as an implicit measure of desire for social intimacy. The experimenters reentered each participant's room and explained that there was a mix-up in the location for their interaction, and then lead each participant to a third room so that the chair arrangements would be preserved. One of the experimenters measured the distance (in inches) between the two chairs placed by each participant while the dyad was taking part in the interaction session.

The other experimenter provided the participants with instructions for the social 
interaction task and two sets of notecards before they began their 20-minute interaction, divided into two segments. To facilitate participants' interactions, questions derived from various intimacy-generating tasks from several past social interaction studies were used (Aron et al., 1997; Page-Gould et al., 2008; Sedikides et al., 1999; Sprecher et al., 2013a; Sprecher et al., 2013b). Additional questions were added to ensure that a breadth of topics was discussed so that participants could accurately judge their partner's selfexpansion opportunity (see Appendix A). Participants took turns choosing a card and responding to the question before asking their partner to respond. After 10 minutes the experimenter knocked and reentered the room to instruct the participants to switch to the second set of questions. After the interaction, participants returned to their original room to complete a second computer survey in reaction to their interaction partner. Finally, the researchers debriefed each participant and thanked him or her for participating in the study.

\section{Pre-Interaction Measures}

The pre-interaction questionnaire was designed to measure a variety of personal variables.

Approach and avoidance motivation

Approach and avoidance motivations were measured using the 24-item Behavioral Inhibition System and Behavioral Activation System scales used in Study 1 (BIS/BAS; Carver \& White, 1994). There was adequate reliability for the two scales (approach, $\alpha=.80$; avoidance, $\alpha=.78$ ). 


\section{Curiosity}

Curiosity was measured using the 10-item Curiosity and Exploration Inventory-II used in Study 1 (CEI-II; Kashdan et al., 2009). There was adequate internal consistency for the CEI-II in this sample, $\alpha=.85$.

Desire for social intimacy

An implicit measure was used to indicate desire for social intimacy based on Vohs et al.'s (2006) measure. For the current study, an experimenter measured the distance between the chairs using a measuring tape while the participants were in a third room interacting. Distance was measured from the center of chair 1 to the center of chair 2 (each marked with a dot) and was reported in inches (to the closest half inch), where a shorter distance equals greater desire for social intimacy.

\section{Post-Interaction Measures}

This questionnaire was designed to assess participants' reactions to their interaction partner. Participants responded to seven scales about their attraction to their interaction partner, such as: romantic liking, opportunity for self-expansion, and perceived compatibility.

\section{Partner's attractiveness}

Individuals' perception of their interaction partner's physical attractiveness was measured on a two-item scale. Items included "How physically attractive was your interaction partner?" and "How sexually attractive was your interaction partner?" Participants indicated their ratings on a 7 -point scale where $1=$ not at all attractive, $3=$ moderately attractive, $7=$ very attractive. This study indicated good reliability for the 
scale, $\alpha=.87$.

Romantic liking

The same five items from Mattingly et al. (2012) that were used in Study 1 were used in Study 2 to measure romantic liking. For example, participants answered questions like "How interested would you be in going on a date with this person?" about their interaction partner. This scale was modified to examine romantic attraction toward one's interaction partner rather than a hypothetical other. There was good internal consistency for romantic liking in this sample, $\alpha=.92$.

Perceived self-expansion opportunity

I measured participants' perceptions of opportunity for self-expansion with a modified version of the "self-expansion desire" scale used in Study 1 (SEQ; Lewandowski \& Aron, 2002). This scale was altered to reflect "interaction partner" rather than a potential partner. This study indicated good reliability for perceived opportunity for self-expansion, $\alpha=.91$.

General perceived compatibility

As in Study 1, I assessed individuals' perceptions regarding their ability to get along with their interaction partner in both a present and future tense. In addition to the three items used in Study 1, a fourth item was added, "My interaction partner 'was on the same page' as me.” This sample displayed good reliability for general perceived compatibility, $\alpha=.89$. 


\section{General perceived similarity}

I assessed perceived similarity to an interaction partner holistically. The two items used in Study 1 were used again in Study 2 (Tidwell et al., 2013); with the addition of one item, "My interaction partner and I seem to have similar interests and hobbies." This study demonstrated good reliability for general perceived similarity, $\alpha=.91$.

\section{Closeness}

I measured participants' closeness toward one's interaction partner using the Inclusion of Other in the Self scale (Aron, Aron, \& Smollan, 1992). This scale included a series of circles that represent the self and the other that become increasingly overlapped. The participant is asked to indicate which set of overlapping circles most represents how close they felt to their interaction partner.

Desire to contact partner

As in Kashdan et al.'s (2011) research, participants were asked whether they would like to share their email address with the other participant as a measure of desire for future interaction. Participants answered by indicating "yes" or "no," but participants" emails were not exchanged to ensure safety.

Demographics

The questionnaire asked participants for their age, gender, ethnic background, year in college, and current relationship status. 


\section{CHAPTER VIII}

\section{RESULTS AND DISCUSSION OF STUDY 2}

\section{Analytic Strategy}

Due to the nesting of two distinguishable individuals in each dyad, I followed procedures outlined by Kenny, Kashy, and Cook (2006) to control for nonindependence of the data. All hypotheses and research questions were tested with multilevel modeling using the MIXED command in SPSS v. 21. Predictors and covariates were grand mean centered before being entered into the model.

\section{Preliminary Analyses}

Table 4 includes descriptive statistics for the variables measured in Study 2: the means, standard deviations, and intercorrelations among the variables. Before testing my main hypotheses for Study 2, I obtained means, standard deviations, and Pearson's correlations for the independent and dependent variables (Table 4). Below I will compare the patterns of findings found in Studies 1 and 2. The averages and standard deviations for participants' scores on each of the individual difference measures (i.e., approach motivation, avoidance motivation, and curiosity) were comparable across studies. However, the averages of individuals' scores on each of the four dependent variables (i.e., romantic liking, self-expansion desire, perceived similarity, and perceived compatibility) in Study 2 were generally lower and more varied than what was reported in Study 1. 
In Study 2, the three independent variables (i.e., approach motivation, avoidance motivation, and curiosity) were again inter-correlated as predicted. Interestingly, the moderate correlations between approach motivation and the four dependent variables found in Study $1(r \mathrm{~s}=.16$ to $.31, p \mathrm{~s}<.05)$ were generally less pronounced and not significant in Study $2(r \mathrm{~s}=.03$ to $-.10, p \mathrm{~s}>.05)$. This pattern was also shown in the correlations between curiosity and three of the four dependent variables for Study $1(r \mathrm{~s}=$ .24 to $.26, p \mathrm{~s}<.01)$ versus Study $2(r \mathrm{~s}=.00$ to $-.03, p \mathrm{~s}>.05)$.

Similar to Study 1, romantic liking was found to be strongly related to opportunity for self-expansion $(r=.64 ; p<.01)$ and perceived compatibility $(r=.67 ; p<.01)$. The correlation between romantic liking and perceived similarity was more pronounced in Study $2(r=.50 ; p<.01)$ compared to Study $1(r=.34, p<.01)$. Several of the correlations between the dependent variables diverged from those found in Study 1. The correlation between opportunity for self-expansion and perceived compatibility nearly doubled from Study $1(r=.32, p<.01)$ to Study $2(r=.60, p<.01)$. Most notably, the relation between opportunity for self-expansion and perceived similarity that was nonsignificant in Study 1 was strong and significant in Study $2(r=.51, p<.01)$. To explore this interesting correlation, I computed the partial correlation between opportunity for self-expansion and perceived similarity, controlling for romantic liking. I found that this relation was less pronounced when controlling for the variance from participants' romantic liking scores, $\operatorname{pr}(105)=.29, p<.01$. 
Table 4

Correlation Matrix, Means, and Standard Deviations for Study 2

\begin{tabular}{|c|c|c|c|c|c|c|c|c|c|}
\hline Measure & 1 & 2 & 3 & 4 & 5 & 6 & 7 & 8 & 9 \\
\hline 1. Approach Motivation & -- & & & & & & & & \\
\hline 2. Avoidance Motivation & -.08 & -- & & & & & & & \\
\hline 3. Curiosity & $.64 * *$ & $-.31 * *$ & -- & & & & & & \\
\hline 4. Social Intimacy Desire & .06 & $-.24 *$ & .04 & -- & & & & & \\
\hline 5. Romantic Liking & -.10 & .11 & -.02 & .10 & -- & & & & \\
\hline 6. Perceived SEO & -.06 & $.25 * *$ & -.03 & .01 & $.64 * *$ & -- & & & \\
\hline 7. Perceived Similarity & .09 & .05 & .15 & .03 & $.50 * *$ & $.51 * *$ & -- & & \\
\hline 8. Perceived Compatibility & .03 & .09 & .00 & .06 & $.67 * *$ & $.60 * *$ & $.74 * *$ & -- & \\
\hline 9. Partner's Attractiveness & $-.20 *$ & .03 & -.03 & -.04 & $.77 * *$ & $.50 * *$ & $.47 * *$ & $.55 * *$ & -- \\
\hline$M$ & 3.24 & 2.93 & 3.64 & 42.77 & 3.70 & 4.47 & 4.16 & 4.58 & 3.78 \\
\hline$S D$ & .38 & .53 & .65 & 7.19 & 1.44 & 1.09 & 1.59 & 1.29 & 1.54 \\
\hline Coefficient $a$ & .80 & .78 & .85 & -- & .92 & .91 & .91 & .89 & .87 \\
\hline
\end{tabular}

$* p<.05 ; * *<<.01$.

\section{Tests of Hypotheses and Research Questions}

\section{Hypothesis 1}

For Hypothesis 1, I predicted that approach motivation would moderate the association between self-expansion opportunity and romantic liking, while controlling for avoidance motivation. In particular, I predicted a strong, positive association between self-expansion opportunity and romantic liking when approach motivation is high and a nonsignificant association between self-expansion opportunity and romantic liking when approach motivation is low. In Model 1, ratings of one's interaction partner's attractiveness, avoidance motivation, approach motivation, and self-expansion opportunity were regressed on romantic liking. In Model 2, these three predictors were entered in addition to the interaction between approach motivation and self-expansion opportunity.

Table 5 displays coefficient estimates of fixed effects using heterogeneous 
compound symmetry. The coefficient for approach motivation was nonsignificant, $F(1$, $85.67)=1.20, p=.14$. The coefficient for perceived self-expansion opportunity was significant, $F(1,100.87)=24.44, p<.001$, suggesting that self-expansion opportunity did indeed predict participants' romantic liking scores. Lastly, approach motivation did not moderate the relation between self-expansion opportunity and romantic liking while controlling for partner's attractiveness and avoidance motivation, $F(1,101.51)=.96, p=$ .17 .

Table 5

Fixed Effects for Approach Motivation as a Moderator of the Relation between SelfExpansion Opportunity and Romantic Liking

\begin{tabular}{lccrrrrr}
\hline & & & & & & \multicolumn{2}{c}{$95 \%$ CI } \\
\cline { 7 - 9 } & Estimate & SE & \multicolumn{1}{c}{$\mathrm{df}$} & \multicolumn{1}{c}{$t$} & \multicolumn{1}{c}{$p$} & Lower & Upper \\
\hline Approach Motivation & .24 & .22 & 85.67 & 1.09 & .14 & -.19 & .67 \\
Self-Expansion Opportunity & .43 & .09 & 100.87 & 4.94 & .00 & .26 & .60 \\
Approach Motivation * SEO & .17 & .17 & 101.51 & .98 & .17 & -.18 & .52 \\
\hline
\end{tabular}

Note. Controlling for partner's attractiveness and avoidance motivation

Hypothesis 1 indicated that approach motivation did not moderate the relation between self-expansion opportunity and romantic liking. Particularly, individuals' approach motivation did not affect the strength of the relation between their ratings of self-expansion opportunity and romantic liking. This finding is contrary to past research, which suggests that approach motivation directly influences indices of relationship initiation (Mattingly et al., 2012) and relationship quality (Impett et al., 2005a; Impett et 
al., 2010; Impett et al., 2005b). The results did indicate a significant, positive relation between self-expansion opportunity and romantic liking, such that individuals who perceived their interaction partner as a source of opportunity simultaneously reported greater liking. This main effect supports previous research on the self-expansion opportunity-attraction link (Lewandowski \& Aron, 2004; Mattingly et al., 2012).

\section{Hypothesis 2}

My second hypothesis predicted that measures of approach motivation and trait curiosity would be positively correlated, and that these measures would negatively correlate with desire for social intimacy. There was a strong, positive correlation between approach motivation and trait-curiosity, $r(108)=.64, p<.001$. Contrary to my prediction, desire for social intimacy was uncorrelated with both approach motivation, $r(101)=.06$, $p=.56$, and trait-curiosity, $r(101)=.04, p=.73$.

This study indicated high convergent validity for approach motivation and trait curiosity as originally found by Kashdan and Roberts (2006). However, it seems as though Vohs and colleagues' (2006) behavioral measure of desire for social intimacy functions more as a measure of low avoidance motivation, $r(101)=-.24, p<.05$, rather than one of high approach motivation.

\section{Exploratory question 1}

In my first exploratory question, I predicted that trait curiosity would moderate the relation between perceived self-expansion opportunity and romantic liking. Ratings of interaction partner's attractiveness, curiosity, and self-expansion opportunity were regressed on romantic liking. In the second model, these three predictors were entered in 
addition to the interaction between curiosity and self-expansion opportunity.

Table 6 displays coefficients estimates of fixed effects using heterogeneous compound symmetry. The coefficient for curiosity was nonsignificant, $F(1,81.62)=.10$, $p=.38$. The coefficient for self-expansion opportunity was significant, $F(1,97.62)=$ 27.04, $p<.001$, suggesting that perceived self-expansion opportunity did indeed predict participants' romantic liking scores. Finally, these results indicate that curiosity did not moderate the relation between self-expansion opportunity and romantic liking while controlling for partner's attractiveness, $F(1,90.43)=.87, p=.18$.

The results of Exploratory Question 1 contradict the results of Kashdan and colleagues' research, which suggests that trait curiosity predicts attraction among strangers in the context of a live-interaction paradigm (Kashdan et al., 2011; Kashdan \& Roberts, 2004; 2006). In their research, Kashdan and colleagues linked trait curiosity to attraction (Kashdan \& Roberts, 2004), closeness (Kashdan et al., 2011), pleasure with the interaction, and desire to contact their partner in the future.

Table 6

Estimates of Fixed Effects for Curiosity as a Moderator of the Relation between SelfExpansion Opportunity and Romantic Liking

\begin{tabular}{lcccrrrrr}
\hline & & & & & & \multicolumn{2}{c}{$95 \%$ CI } \\
\cline { 3 - 5 } & Estimate & SE & df & \multicolumn{1}{c}{$t$} & $p$ & Lower & Upper \\
\hline Curiosity & .04 & .12 & 81.62 & .30 & .38 & -.20 & .27 \\
Self-Expansion Opportunity & .44 & .08 & 97.62 & 5.20 & .00 & .27 & .60 \\
Curiosity* SEO & .11 & .12 & 90.42 & .93 & .18 & -.13 & .36 \\
\hline
\end{tabular}

Note. Controlling for partner's attractiveness 


\section{Exploratory question 2}

My second exploratory question asked how much of the variance did approach motivation, curiosity, and self-expansion opportunity account for in participants' ratings of romantic liking and desire to contact their partner, while controlling for avoidance motivation and their partner's attractiveness. This question was assessed using two hierarchical regression analyses.

The first hierarchical regression analysis was conducted to explore romantic liking. In the first step of the regression analysis, I entered dyad and sex as control variables. In the second step of the regression analysis, avoidance motivation and partner's attractiveness were entered. Finally, in the third step of the analysis, approach motivation, trait curiosity, and self-expansion opportunity was regressed on romantic liking.

Table 7 presents the regression coefficients for the abovementioned variables at each stage of the hierarchical regression analysis. Dyad and sex were entered into step 1 of the regression model to control for nonindependence of the data. These variables did not account for a significant portion of the variance in romantic liking, $F(2,105)=.12, R^{2}$ $=.002, p=.89$. Next, participants' avoidance motivation and perceptions of their partner's attractiveness were added to this model, resulting in a significant amount of variance explained, $\Delta F(2,103)=79.17, \Delta R^{2}=.61, p<.001$. Lastly, adding approach motivation, trait curiosity, and perceived self-expansion opportunity to the model in step 3 increased the percentage of variance explained, $\Delta F(3,100)=9.68, \Delta R^{2}=.09, p<.001$. Overall, this model explained $70 \%$ of the variance in romantic liking, $F(7,100)=32.60$, 
$p<.001$.

Table 7

Hierarchical Regression Analysis for Romantic Liking

\begin{tabular}{lccccc}
\hline \multicolumn{1}{c}{ Variable } & $\beta$ & $S E$ & $t$ & $R^{2}$ & $\Delta R^{2}$ \\
\hline Step 1 & & & & .002 & \\
$\quad$ Dyad & .04 & .01 & -.38 & & \\
$\quad$ Sex & .03 & .14 & .30 & & \\
Step 2 & & & & $.61^{*}$ & $.61^{*}$ \\
$\quad$ Partner's Attractiveness & .78 & .06 & $12.41^{*}$ & & \\
$\quad$ Avoidance Motivation & .09 & .18 & 1.32 & & \\
Step 3 & & & & $.70^{*}$ & $.09^{*}$ \\
$\quad$ Approach Motivation & .05 & .29 & .70 & & \\
$\quad$ Trait Curiosity & -.03 & .17 & -.44 & & \\
$\quad$ Self-Expansion Opportunity & .36 & .09 & $5.27^{*}$ & & \\
\hline
\end{tabular}

Note. ${ }^{*} p<.001$.

The second portion of this hypothesis asked how much of the variance did approach motivation, curiosity, and self-expansion opportunity account for in participants' desire to contact their partner in the future, while controlling for avoidance motivation and their partner's attractiveness. This question was assessed using a second hierarchical regression analysis.

Table 8 includes the regression coefficients for the abovementioned variables at each stage of the hierarchical regression analysis. Again, dyad and sex were entered into step 1 of the regression model to account for nonindependence of the data. These variables did not account for a significant portion of the variance in participants' desire to contact their partner, $F(2,103)=.87, R^{2}=.02, p=.42$. Next, participants' avoidance 
motivation and perceptions of their partner's attractiveness were added to the model, resulting in a significant amount of variance explained, $\Delta F(2,101)=13.83, \Delta R^{2}=.21, p$ $<$.001. Lastly, adding approach motivation, trait curiosity, and perceived self-expansion opportunity to the model in step 3 did not increase the percentage of variance explained, $\Delta F(3,98)=1.82, \Delta R^{2}=.04, p=.15$. Overall, this model explained $27 \%$ of the variance in participants' desire to contact their partner, $F(7,98)=5.14, p<.001$.

Table 8

Hierarchical Regression Analysis for Participants' Desire to Contact their Partner

\begin{tabular}{lccccc}
\hline \multicolumn{1}{c}{ Variable } & $\beta$ & $S E$ & $t$ & $R^{2}$ & $\Delta R^{2}$ \\
\hline Step 1 & & & & .02 & \\
$\quad$ Dyad & -.10 & .003 & -.99 & & \\
$\quad$ Sex & .08 & .05 & .86 & & $.23^{*}$ \\
Step 2 & & & & $.21^{*}$ \\
$\quad$ Partner's Attractiveness & .46 & .03 & $5.22^{*}$ & & \\
$\quad$ Avoidance Motivation & .03 & .09 & .27 & & $.27 *$ \\
Step 3 & & & & .04 \\
$\quad$ Approach Motivation & .22 & .16 & 1.84 & & \\
$\quad$ Trait Curiosity & -.12 & .09 & -.94 & & \\
$\quad$ Self-Expansion Opportunity & .13 & .05 & 1.26 & & \\
\hline
\end{tabular}

Note. ${ }^{*} p<.001$.

Contrary to my prediction, approach motivation, trait curiosity, and selfexpansion opportunity did not together account for a significant portion of the variance in romantic liking. A hierarchical regression analysis indicated that partner's attractiveness and self-expansion opportunity explained the greatest proportion of variance. Likewise, the second hierarchical regression analysis produced similar findings, such that approach 
motivation, trait curiosity, and self-expansion opportunity did not together account for a significant percentage of the variance in participants' desire to contact their partner. This analysis revealed that partner's attractiveness was a driving force in participants' desire to contact them again in the future. 


\section{CHAPTER IX}

\section{GENERAL DISCUSSION}

Existing literature on the self-expansion model suggests that self-expanding is a powerful relationship maintenance strategy (Agnew et al., 1998; Aron et al., 2000; Graham, 2008; Lewandowski \& Aron, 2004; Reissman et al., 1993). Likewise, literature on various motivational orientations reveal that individuals with high self-expansion motivation experience greater positive affect, closeness, and relationship quality than those with low motivation (Aron et al., 2000; Carver \& White, 1994; Graham, 2008; Impett et al., 2005; Kashdan et al., 2004; Mattingly \& Clark, 2012; Mattingly et al., 2012; Neff \& Harter, 2002; Reissman et al., 1993). Until recently, there has been little research on how people of different motivational orientations decide with whom to pursue a relationship. What I had expected my studies would reveal is that individuals' appraisals of a potential partner's self-expansion opportunities contribute to attraction for highly motived individuals. Mattingly et al. (2012) demonstrated this pattern in a vignette study; however, there were concerns about the operationalization of low self-expansion opportunity.

Study 1 provided an opportunity to test the validity of Mattingly et al.'s (2012) low self-expansion opportunity vignette. As predicted, the difference in ratings of attraction between the low and high motivators was likely due to the negative wording used to describe low self-expansion opportunity. Study 1 also revealed that there were no 
significant differences in perceptions of the target's self-expansion opportunity between participants in the activity condition and participants in the knowledge condition. It is possible that the manipulation for type of self-expansion was too subtle to be reflected upon or that participants view these two types of self-expansion similarly. Further research would be needed to determine whether it is the strength of the manipulation or if the two types of opportunity are not considered differently.

Study 2 was designed to extend Mattingly et al.’s (2012) study by investigating the influence of self-expansion motivation on relationship initiation in a live social interaction context. As previously mentioned, the closeness-generating task is an ideal "thin slice" approach to investigating early perceptions of a potential partner. Unfortunately, this study did not replicate the moderation analysis that Mattingly and colleagues (2012) had found. The current study also employed a novel behavioral measure of desire for social intimacy. My second hypothesis was partially supported, such that approach motivation and trait curiosity were strongly, positively correlated, however, both were unrelated to desire for social intimacy. Interestingly, desire for social intimacy was negatively related to avoidance motivation, such that individuals low in avoidance motivation put a greater distance between chairs than individuals high in avoidance motivation. Finally, perceptions of an interaction partner's attractiveness and opportunities for self-expansion explained the greatest percentage of variance in individuals' ratings of romantic liking. Greater perceptions of attractiveness and selfexpansion opportunity were associated with greater romantic liking.

A final interesting finding was the nature of the relations among perceived 
similarity, self-expansion opportunity, and romantic liking. The theoretical underpinnings of the self-expansion model suggest that a person (e.g., a potential romantic partner) who provides self-expanding opportunities is also (and by definition) somewhat dissimilar from the self (Aron et al., 2001). However, Study 2 revealed a strong and positive relation between perceived self-expansion opportunity and perceived similarity. It is possible that the self-expansion questions, which were used to measure perceptions of opportunity, actually tap individuals' opinions of whether their interaction partner would be willing to engage in self-expanding activities with them. Therefore, it would be measuring the degree of motivational similarity that participants felt toward their partners. On a similar note, ratings of similarity may have been skewed because selfconcept overlap between individuals occurs quite rapidly. Slotter and Gardner (2008) discussed just how rapidly another's qualities are incorporated into the self, especially when romantic motives are primed. Because the participants in Study 2 answered questions about their interaction partner's attractiveness before completing the selfexpansion questionnaire, it is possible that they too were primed to think of their partner in a romantic context. Regrettably, romantic motives were not measured or manipulated in the current study. Therefore, it might be necessary to remove any cues of romantic potential to be able to get a pure measure of perceived self-expansion opportunity. Researchers may consider priming for friendship versus priming for attraction to parse out variance due to self-expansion opportunity versus romantic liking.

There are several reasons why I believe approach motivation and self-expansion opportunity were not shown to interact and, consequently, affect romantic liking in Study 
2. One reason why approach motivation may not have surfaced as a moderator may be due to the fact that there was little variability in my measure of self-expansion motivation for this particular sample. It is possible that participants were homogenous in their ratings of approach motivation $(M=3.24, S D=.38)$ and trait curiosity $(M=3.64, S D=.65)$. Normative data for the BIS/BAS scale indicates that the mean score of my sample was slightly higher than that found in a community sample of 58918 to 29 year olds (Men: $M$ $=3.08, S D=.37$; Women: $M=3.09, S D=.39$; Jorm et al., 1998). Participants in this study self-selected to participate in a laboratory study for research credit, possibly indicating a greater tendency to engage in novel experiences. However, these individuals were not aware of the social interaction task that they would be engaging in until informed consent procedures were administered. Nevertheless, in this sample, there was low variability in the scores of approach motivation and perceived self-expansion opportunity. Homogeneity of participants' approach motivation scores may have created low and high motivation groups (using -1 and $+1 \mathrm{SD}$ around the mean) that do not reflect participants' true classification. For example, individuals whose mean scores were equal to or less than 2.86 were considered low approach motivators and those higher than or equal to 3.62 were considered highly approach oriented. A sample with greater diversity in approach motivation may have made this interaction distinguishable.

A second potential explanation for why approach motivation did not moderate the link between self-expansion opportunity and romantic liking is also related to the lack of variability in this study. There was not a representative sample of individuals who exhibit lower self-expansion opportunity in Study 2. Given that the sample included those 
enrolled in college, there may be pre-existing differences between college students and non-college students in in their education and experiences. Likewise, it is possible that the self-expansion literature does not accurately portray the variance in self-expansion opportunity because the majority of past studies have been based on samples with dating couples. Therefore, individuals low in self-expansion opportunity may not maintain successful relationships, and not be represented in the literature.

The third possible explanation is that individuals' perceptions of others' opportunities may have been biased through participants' attempts at impression management. When two people meet for the first time, they often attempt to put their best face forward, or manage others' impressions of the self (Baumeister, 1982). Often, these individuals attempt to reconcile their actual and ideal selves by controlling other's perceptions of the self to match their ideal. Therefore, Study 2 participants may have engaged in attempts to manage their self-presentation by trying to make others perceive them as interesting or fun throughout the social interaction task. Past research suggests that this strategy may work - participants instructed to "put their best face forward" elicited more positive and accurate impressions from others than a control group (Human, Biensanz, Parisotto, \& Dunn, 2012).

In a similar vein, it is possible that everyone was similarly attracted to potential partners who were high in self-expansion opportunity, regardless of their own motives. I propose this explanation because recent research from Zhou and Wright (under review) found that people are attracted to others who most exemplify traits that are represented in their ideal self (under review; as cited in Aron, Lewandowski, Mashek, \& Aron, 2013, p. 
94). Thus, it is possible that many people see self-expanding as a positive process that reaps numerous benefits to the self (i.e., closeness, positive affect, enjoyment). In turn, these participants may believe that a relationship with someone high in self-expansion opportunity would bring them closer to their ideal self.

\section{Strengths, Limitations, and Future Directions}

There were various methodological strengths of the current set of studies. First, Study 1 clarified the vignettes originally developed by Mattingly et al. (2012) and incorporated additional measures of self-expansion motivation and attraction to extend the current literature. Study 2 used an ecologically valid method for generating closeness between strangers that is frequently used to study relationship initiation (Aron et al., 1997; Page-Gould et al., 2008; Sedikides et al., 1999; Sprecher et al., 2013a; Sprecher et al., 2013b). Additionally, Study 2 incorporated two behavioral measures: desire for social intimacy, which was obtained using the chair task, and a behavioral index of closeness, which asked participants if they would like to exchange email addresses.

One limitation of the current study was the weak presentation of the differing types of self-expansion opportunity in Study 1. In the future, researchers should consider classifying different types of self-expansion opportunity, to see if certain people are drawn to different categories of expansion (e.g., cultural [museums, Broadway, leisure reading], athletic [fitness, team sports, marathons]) than others, as perceptions of selfexpansion opportunity are subjective by nature. In the current study, vignettes used originally by Mattingly et al. only included a vague description of the self-expansion opportunity that a target has to offer. 
Another limitation of this research was that the "thin slice" approach to studying relationship initiation may have been too brief. It is possible that individuals felt more inclined to self-present knowing that they were unlikely to continue their relationship with their interaction partner beyond their participation in the study. However, this can be said of any situation when you meet someone for the first time. It is difficult to know for certain when you meet someone for the first time whether your interaction will continue past that thin slice. Likewise, this brief (20-minute) laboratory encounter did not allow participants to engage in self-expansion together beyond the self-expansion they felt from conversing with someone new. A key element of relationship initiation incorporates the positive affect that participants feel while self-expanding with another person (Aron et al., 2001). Essentially, this laboratory study investigated the pre-initiation phase of the relationship initiation process, which captured the first glimpse of a potential relationship.

Given the intermediate level of theoretical maturity of the self-expansion model, the current research revealed that more descriptive information is needed to inform the operational definitions of self-expansion motivation and self-expansion opportunity in future studies. The bulk of the literature on the self-expansion model focuses on relationship maintenance. The current research contributes to the understanding of how self-expansion opportunity influences relationship initiation, or the initial phases where one first decides if they which to pursue relationship initiation. Finally, most of the selfexpansion motivation literature focuses on self-expansion in the context of a romantic relationship; future research may wish to test this theory with the development and maintenance of nonromantic relationships (i.e., family, co-workers, friends) or on one's 
own. It is also possible that too many other factors are at play in the formation of new romantic relationships (e.g., physical attraction) that self-expansion motivation and selfexpansion opportunity may play a less important role. Moreover, as noted previously, given the potentially rapid nature in which a potential romantic partner becomes immersed in the self, more nuanced methods would be required.

There are several aspects of the current studies that researchers should investigate further. One line of inquiry should focus on the desirability of self-expansion. Specifically, research may identify if self-expansion is desirable to everyone and the frequency that motives to self-expand are incorporated in individuals' ideal self (i.e., I wish I engaged in more behaviors that would expand my sense of self). Additionally, future research should manipulate participants' perceptions of self-expansion opportunity in a live context. This would give us a better idea of the role that self-expansion opportunity plays in individuals' criteria for evaluating potential partners.

\section{Conclusions}

Nearly 30 years of research has established Aron and colleagues' self-expansion model as an important theory for evaluating relationship initiation, maintenance, and dissolution (Aron et al., 2001). The purpose of this set of studies was to further delineate how self-expansion motivation and opportunity influence attraction. Results from both studies indicate that perceptions of self-expansion opportunity play an integral role in perceptions of romantic liking. Nevertheless, the current research failed to incorporate self-expansion motivation as a moderator of this relation, as shown by Mattingly and colleagues (2012). 


\section{REFERENCES}

Agnew, C. R., Van Lange, P. A. M., Rusbult, C. E., \& Langston, C. A. (1998). Cognitive interdependence: Commitment and the mental representation of close relationships. Journal of Personality and Social Psychology, 74, 939-954.

Albright, L., Kenny, D. A., \& Malloy, T. E. (1988). Consensus in personality judgments at zero acquaintance. Journal of Personality and Social Psychology, 55, 387-395.

Amabile, T. M. (1983). The Social Psychology of Creativity. New York: Springer-Verlag.

Ambady, N., \& Rosenthal, R. (1993). Half a minute: predicting teacher evaluations from thin slices of nonverbal behavior and physical attractiveness. Journal of Personality and Social Psychology, 64, 431-441.

Amodio, D. M., \& Showers, C. J. (2005). "Similarity breeds liking” revisited: The moderating role of commitment. Journal of Social and Personal Relationships, $22,817-836$.

Aron, A., \& Aron, E. N. (1986). Love and the expansion of self: Understanding attraction and satisfaction. New York: Hemisphere.

Aron, E. N. \& Aron, A. (1996). Love and expansion of the self: The state of the model. Personal Relationships, 3, 45-58.

Aron, A., Aron, E. N., \& Norman, C. (2001). Self-expansion model of motivation and cognition in close relationships and beyond. In M. Clark \& G. Fletcher (Eds.), Blackwell's handbook of social psychology, Vol. 2: Interpersonal processes (pp. 478-502). Oxford: Blackwell.

Aron, A., Aron E. N., \& Smollan, D. (1992). Inclusion of other in the self scale and the structure of interpersonal closeness. Journal of Personality and Social Psychology, 63, 596-612.

Aron, A., Fisher, H. E., Mashek, D. J., Strong, G., Li., H., Brown, L. L. (2005). Reward, motivation and emotion systems associated with early-stage intense romantic love. Journal of Neurophysiology, 94, 327-337.

Aron, A., Lewandowski Jr., G. W., Mashek, D., \& Aron, E. N. (2013). The selfexpansion model of motivation and cognition in close relationships. In J. A. 
Simpson \& L. Campbell (Eds.) The Oxford handbook of close relationships (pp. 90-115). New York: Oxford University Press.

Aron, A., Melinat, E., Aron, E. N., Vallone, R., \& Bator, R. (1997). The experimental generation of interpersonal closeness: A procedure and some preliminary findings. Personality and Social Psychology Bulletin, 23, 363-377.

Aron, A., Norman, C. C., Aron, E. N., McKenna, C., \& Heyman, R. E. (2000). Couples' shared participation in novel and arousing activities and experienced relationship quality. Journal of Personality and Social Psychology, 78, 273-284.

Aron, A., Paris, M., \& Aron, E. N. (1995). Falling in love: Prospective studies of selfconcept change. Journal of Personality and Social Psychology, 69, 1102-1112.

Aron, A., Steele, J. L., Kashdan, T. B., \& Perez, M. (2006). When similars do not attract: Tests of a prediction from the self-expansion model. Personal Relationships, 13, 387-396.

Baumeister, R. F. (1982). A self-presentational view of social phenomena. Psychological Bulletin, 91, 3-26.

Baumeister, R. F., \& Leary, M. R. (1995). The need to belong: Desire for interpersonal attachments as a fundamental human motivation. Psychological Bulletin, 117, 497-529.

Blais, M. R., Sabourin, S., Boucher, C., \& Vallerand, R. J. (1990). Toward a motivational model of couple happiness. Journal of Personality and Social Psychology, 59, 1021-1031.

Bredow, C. A., Cate, R. M., \& Huston, T. L. (2008). Have we met before? A conceptual model of first romantic encounters. In S. Sprecher, A. Wenzel, and J. H. Harvey (Eds.), Handbook of relationship initiation (pp. 3-28). New York, NY: Taylor \& Francis.

Byrne, D. (1997). An overview (and underview) of research and theory within the attraction paradigm. Journal of Social and Personal Relationships, 14, 417-431.

Carson, J. W., Carson, K. M., Gil, K. M., \& Baucom, D. H. (2007). Self-expansion as a mediator of relationship improvements in a mindfulness intervention. Journal of Marital \& Family Therapy, 33, 517-528.

Carver, C. S., \& White, T. L. (1994). Behavioral inhibition, behavioral activation, and affective responses to impending reward and punishment: The BIS/BAS scales. Journal of Personality and Social Psychology, 67, 319-333.

Deci, E. L., \& Ryan, R. M. (1985). Intrinsic motivation and self-determination in human 
behavior. New York: Plenum.

Deci, E. L., \& Ryan, R. M. (1991). A motivational approach to self: Integration in personality. In R. Dienstbier (Ed.), Nebraska symposium on motivation: Perspectives on motivation, Vol. 38. (pp. 237-288). Lincoln, NE: University Of Nebraska Press.

Diener, E., \& Seligman, M. E. P. (2002). Very happy people. Psychological Science, 13, 80-83.

Eastwick, P. W., \& Finkel, E. J. (2008). Speed-dating: A powerful and flexible paradigm for studying romantic relationship initiation. In S. Sprecher, A. Wenzel, \& J. Harvey (Eds.), Handbook of relationship initiation (pp. 217-234). New York: Guilford.

Elliot, A. J., Gable, S. L., \& Mapes, R. R. (2006). Approach and avoidance motivation in the social domain. Personality and Social Psychology Bulletin, 32, 378-391.

Fredrickson, B. L. (2004). The broaden-and-build theory of positive emotions. Philos Trans R Soc Lond B Biol Sci, 359, 1367-1378.

Gable, S. L. (2006). Approach and avoidance social motives and goals. Journal of Personality, 71, 175-222.

Gable, S., Reis, H., \& Elliot, A.J. (2003). Evidence for bivarate systems: An empirical test of appetition and aversion across domains. Journal of Research in Personality, 37, 349-372.

Gordon, C. L., \& Baucom, D. H. (2009). Examining the individual within marriage: Personal strengths and relationship satisfaction. Personal Relationships, 16, 421435 .

Gordon, C. L., \& Lou, S. (2011). The Personal Expansion Questionnaire: Measuring one's tendency to expand through novelty and augmentation. Personality and Individual Differences, 51, 89-94.

Graham, J. M. (2008). Self-expansion and flow in couples' momentary experiences: an experience sampling study. Journal of Personality and Social Psychology, 95, 679-694.

Gray, J. A. (1987). The psychology of fear and stress. Cambridge: Cambridge University Press.

Hodgins, H. S., \& Knee, C. R. (2002). The integrating self and conscious experience. In E. L. Deci \& R. M. Ryan (Eds.), Handbook of self-determination research. (pp. 87-100). Rochester, NY: University of Rochester Press. 
Human, L. J., Biesanz, J. C., Parisotto, K. L., \& Dunn, E. W. (2012). Your best self helps reveal your true self: Positive self-presentation leads to more accurate personality impressions. Social Psychological and Personality Science, 3, 23-30.

Impett, E. A., Gable, S. L., \& Peplau, L. A. (2005a). Giving up and giving in: The costs and benefits of daily sacrifice in intimate relationships. Journal of Personality and Social Psychology, 89, 327-344.

Impett, E. A., Gordon, A., Kogan, A., Oveis, C., Gable, S. L., \& Keltner, D. (2010). Moving toward more perfect unions: Daily and long-term consequences of approach and avoidance goals in romantic relationships. Journal of Personality and Social Psychology, 99, 948-963.

Impett, E. A., Peplau, L. A., \& Gable, S. L. (2005b). Approach and avoidance sexual motivation: Implications for personal and interpersonal well-being. Personal Relationships, 12, 465-482.

Impett, E., A., Strachman, A., Finkel, E. J., \& Gable, S. L. (2008). Maintaining sexual desire in intimate relationships: The importance of approach goals. Journal of Personality and Social Psychology, 94, 808-823.

Isen, A. M. (2000). Positive affect and decision making. In M. Lewis \& J. HavilandJones (Eds.), Handbook of emotions (2nd ed., pp. 417-435). New York: Guilford.

Jorm, A. F., Christensen, H., Henderson, A. S., Jacomb, P. A., Korten, A. E., \& Rogers, B. (1998). Using the BIS/BAS sclaes to measure behavioural inhibition and behavioral activation: Factor structure, validity and norms in a large community sample. Personality and Individual Differences, 26, 49-58.

Kashdan, T. B., Gallagher, M. W., Silvia, P. J., Winterstein, B. P., Breen, W. E., Terhar, D., \& Steger, M. F. (2009). The Curiosity and Exploration Inventory-II: Development, factor structure, and psychometrics. Journal of Research in Personality, 43(6), 987-998.

Kashdan, T. B., McKnight, P. E., Fincham, F. D., \& Rose, P. (2011). When curiosity breeds intimacy: Taking advantage of intimacy opportunities and transforming boring conversations. Journal of Personality, 79, 1369-1401.

Kashdan, T. B., \& Roberts, J. E. (2004). Trait and state curiosity in the genesis of intimacy: Differentiation from related constructs. Journal of Social and Clinical Psychology, 23, 792-816.

Kashdan, T. B., \& Roberts, J. E. (2006). Affective outcomes and cognitive processes in superficial and intimate interactions: Roles of social anxiety and curiosity. Journal of Research in Personality, 40, 140-167.

Kashdan, T. B., Rose, P., \& Fincham, F. D. (2004). Curiosity and exploration: 
Facilitating positive subjective experiences and personal growth opportunities. Journal of Personality Assessment, 82, 291-305.

Kashdan, T. B., \& Steger, M. F. (2007). Curiosity and pathways to well-being and meaning in life: Traits, states, and everyday behaviors. Motivation and Emotion, 31, 159-173.

Kenny, D. A., Kashy, D. A., \& Cook, W. L. (2006). Dyadic data analysis. Guilford Press.

Knee, C. R. (1998). Implicit theories of relationships: Assessment and prediction of romantic relationship initiation, coping, and longevity. Journal of Personality and Social Psychology, 74, 360-370.

Knee, C. R., Nanayakkara, A., Vietor, N. A., Neighbors, C., \& Patrick, H. (2001). Implicit theories of relationships: Who cares if romantic partners are less than ideal? Personality and Social Psychology Bulletin, 27, 808-819.

Knee, C. R., Patrick, H., Vietor, N. A., Nanayakkara, A., Neighbors, C. (2002). Selfdetermination as growth motivation in romantic relationships. Personality and Social Psychology Bulletin, 28, 609-619.

Koestner, R., Ryan, R. M., Bernieri, F., \& Holt, K (1984). Setting limits on children's behavior: The differential effects of controlling versus informational styles on children's intrinsic motivation and creativity. Journal of Personality, 54, 233-248.

Larson, R. W., \& Verma, S. (1999). How children and adolescents spend time across the world: Work, play, and developmental opportunities. Psychological Bulletin, 125, 701-736.

Leary, M. R. (2007). Motivational and emotional aspects of the self. Annual Review of Psychology, 58, 317-344.

Lewandowski, G. W., Jr., \& Aron, A. (2002, February). The Self-expansion Scale: Construction and validation. Paper presented at the Third Annual Meeting of the Society of Personality and Social Psychology, Savannah, GA.

Lewandowski, G. W., Jr., \& Aron, A. (2004). Distinguishing arousal from novelty and challenge in initial romantic attraction between strangers. Social Behavior and Personality, 32, 361-372.

Maslow, A. H. (1970). Motivation and personality. Harper \& Row: New York.

Mattingly, B. A., \& Clark, E. M. (2012). Weakening relationships we try to preserve: Motivated sacrifice, attachment, and relationship quality. Journal of Applied Social Psychology, 42, 373-386. 
Mattingly, B. A., McIntyre, K. P., \& Lewandowski, G. W., Jr. (2012). Approach motivation and the expansion of self in close relationships. Personal Relationships, 19, 113-127.

McAdams, D. P. (1984). Human motives and personal relationships communication. In Y J. Derlega (Ed.), Intimacy and close relationships (pp. 41-71). New York: Academic Press.

Montoya, R. M., Horton, R. S., \& Kirchner, J. (2008). Is actual similarity necessary for attraction? A meta-analysis of actual and perceived similarity. Journal of Social and Personal Relationships, 25, 889-923.

Neff, K. D., \& Harter, S. (2002). The role of power and authenticity in relationship styles emphasizing autonomy, connectedness, or mutuality among adult couples. Journal of Social and Personal Relationships, 19, 835-857.

Page-Gould, E., Mendoza-Denton, R., \& Tropp, L. R. (2008). With a little help from my cross-group friend: Reducing intergroup anxiety through cross-group friendship. Journal of Personality and Social Psychology, 95, 1080-1094.

Pittman, T. S, \& Heller, J. F. (1987). Social motivation. Annual Review of Psychology, $38,461-489$.

Reis, H. T., Collins, W. A., \& Berscheid, E. (2000). The relationship context of human behavior and development. Psychological Bulletin, 126, 844-872.

Reis, H. T., Maniaci, M. R., Caprariello, P. A., Eastwick, P. W., \& Finkel, E. J. (2011). Familiarity does indeed promote attraction in live interaction. Journal of Personality and Social Psychology, 101, 557-570.

Reissman, C., Aron, A., \& Bergen, M. R. (1993). Shared activities and marital satisfaction: Causal direction and self-expansion versus boredom. Journal of Social and Personal Relationships, 10, 243-254.

Rempel, J. K, Holmes, J. G, \& Zanna, M. P. (1985). Trust in close relationships. Journal of Personality and Social Psychology, 49, 95-112.

Ryan, R. M., Mims, V., \& Koestner, R. (1983). Relation of reward contingency and interpersonal context to intrinsic motivation: A review and test using cognitive evaluation theory. Journal of Personality and Social Psychology, 45, 736-750.

Sedikides, C., Campbell, W. K., Reeder, G. D., \& Elliot, A. J. (1999). The relationship closeness induction task. Representative Research in Social Psychology, 23, 1-4.

Seligman, C, Fazio, R. H, \& Zanna, M. P. (1980). Effects of salience of extrinsic rewards on liking and loving. Journal of Personality and Social Psychology, 38, 453-460. 
Slotter, E. B., \& Gardner, W. L. (2009). Where do you end and I begin? Evidence for anticipatory, motivated self-other integration between relationship partners. Journal of Personality and Social Psychology, 96, 1137-1151.

Sprecher, S., Treger, S., \& Wondra, J. D. (2013a). Effects of disclosure role on liking and other reactions in get-acquainted interactions. Journal of Social and Personal Relationships, 30, 497-514.

Sprecher, S., Treger, S., Wondra, J. D., Hilaire, N., \& Wallpe, K. (2013b). Taking turns: Reciprocal self-disclosure promotes liking in initial interactions. Journal of Experimental Social Psychology, 49, 860-866.

Strong, G., Fincham, F., \& Aron, A. (2009). When nothing bad happens but you're still unhappy: Boredom in romantic relationships. In Mind, 8 .

Sunnafrank, M. (1983). Attitude similarity and interpersonal attraction in communication processes: In pursuit of an ephemeral influence. Communication Monographs, 50, 273-284.

Sunnafrank, M. J., \& Miller, G. R. (1981). The role of initial conversations in determining attraction to similar and dissimilar strangers. Human Communication Research, 8, 16-25.

Tidwell, N. D., Eastwick, P. W., \& Finkel, E. J. (2013). Perceived, not actual, similarity predicts initial attraction in a live romantic context: Evidence from the speeddating paradigm. Personal Relationships, 20, 199-215.

Tsapelas, I., Aron, A., \& Orbuch, T. (2009). Marital boredom now predicts less satisfaction 9 years later. Psychological Science, 20, 543-545.

Vohs, K. D., Mead, N. L., \& Goode, M. R. (2006). Psychological consequences of money. Science, 314, 1154-1156.

Waugh, C. E., \& Fredrickson, B. L. (2006). Nice to know you: Positive emotions, selfother overlap, and complex understanding in the formation of new relationships. Journal of Positive Psychology, 1, 93-106. 


\section{APPENDIX \\ QUESTION SETS FOR SOCIAL \\ INTERACTION TASK}

\section{Set 1}

1. What is your favorite thing to do?

2. What would constitute a "perfect" day for you?

3. If you could take a one-month trip anywhere in the world and money were not a consideration, where would you go and what would you do?

4. What do you do that others would consider unique?

5. When was the last time you tried a new food? What was it?

6. What are a few things on your bucket list?

7. Given the choice of anyone in the world, whom would you want as a dinner guest?

8. What was the last thing you "Googled" just because you wanted to learn more about it?

9. Whom do you admire most? In what way does that person inspire you?

10. Do you have any specific long-term goals? What is one and how do you plan on reaching it?

11. What would your ideal or perfect life be like?

12. What is your most memorable trip or vacation? What made it memorable?

13. If a crystal ball could tell you the truth about yourself, your life, the future, or 
anything else, what would you want to know?

14. What is the greatest accomplishment of your life?

15. If you could wake up tomorrow having gained any one quality or ability, what would it be?

16. What is your favorite book? Why?

\section{Set 2}

1. What do you do that makes you feel good about yourself?

2. What is your most treasured memory?

3. Describe an activity that you enjoy participating in.

4. What do you like best about your life? Least?

5. Do you believe in any sort of God? If not, do you think you might still pray if you were in a life-threatening situation?

6. Describe a skill you possess that you feel few others do.

7. Is there something that you've dreamed of doing for a long time? Why haven't you done it?

8. Describe an area that you are very knowledgeable about.

9. Is there anything in your life that you regret doing? What about not doing? Why?

10. If you knew that in one year you would die suddenly, would you change anything about the way you are now living? Why?

11. What events in your life have shaped who you are today?

12. Do you believe our life is predetermined by fate or is solely a consequence of the 
choices we make (or both)? Explain why.

13. Can you envision how you are likely to look back upon the things you are doing today? If so, how much do you try to live now as you think you will one day wish you had lived?

14. For what in your life do you feel most grateful?

15. Would you like to be famous? In what way?

16. If you could change anything about the way you were raised, what would it be? 